TI 2015-095/III

Tinbergen Institute Discussion Paper
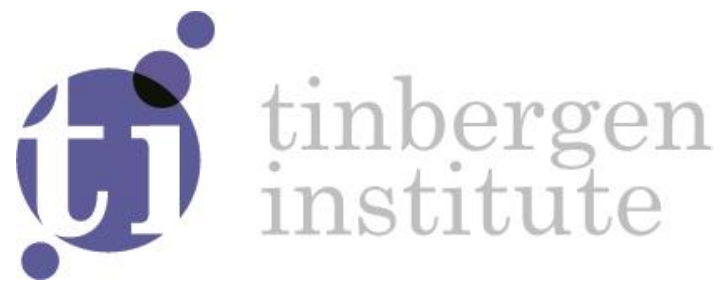

\title{
What Do Professional Forecasters Actually Predict?
}

\section{Revision: 13-10-2017}

Didier Nibbering ${ }^{1,2}$

Richard Paap ${ }^{2}$

Michel van der Wel ${ }^{2}$

\footnotetext{
${ }^{1}$ Econometric Institute, Erasmus University Rotterdam

${ }^{2}$ Erasmus University Rotterdam; Tinbergen Institute, The Netherlands
} 
Tinbergen Institute is the graduate school and research institute in economics of Erasmus University Rotterdam, the University of Amsterdam and VU University Amsterdam.

Contact: discussionpapers@tinbergen.nl

More TI discussion papers can be downloaded at http://www.tinbergen.nl

Tinbergen Institute has two locations:

Tinbergen Institute Amsterdam

Gustav Mahlerplein 117

1082 MS Amsterdam

The Netherlands

Tel.: +31(0)205984580

Tinbergen Institute Rotterdam

Burg. Oudlaan 50

3062 PA Rotterdam

The Netherlands

Tel.: +31(0)10408 8900 


\title{
What Do Professional Forecasters Actually Predict?*
}

\author{
Didier Nibbering ${ }^{\dagger} \quad$ Richard Paap Michel van der Wel \\ Econometric Institute, Tinbergen Institute, Erasmus University Rotterdam
}

October 13, 2017

\begin{abstract}
In this paper we study what professional forecasters predict. We use spectral analysis and state space modeling to decompose economic time series into a trend, business-cycle, and irregular component. To examine which components are captured by professional forecasters, we regress their forecasts on the estimated components extracted from both the spectral analysis and the state space model. For both decomposition methods we find that the Survey of Professional Forecasters in the short run can predict almost all variation in the time series due to the trend and business-cycle, but the forecasts contain little or no significant information about the variation in the irregular component.
\end{abstract}

Keywords: Forecast Evaluation, Survey of Professional Forecasters, Expert Forecast, Trend-Cycle Decomposition, State Space Modeling, Baxter-King Filter

${ }^{*}$ We thank three anonymous reviewers and the associate editor for their comments and suggestions. Thanks are also due to Alain Hecq, Cem Çakmaklı, Philip Hans Franses and conference participants at the 20th meeting of the Netherlands Econometric Study Group (2015), the 2nd Annual Conference of the International Association for Applied Econometrics (2015), the 11th World Congress of the Econometric Society (2015), and seminar participants at the Tinbergen Institute, Erasmus University Rotterdam.

${ }^{\dagger}$ Correspondence to: Didier Nibbering, Econometric Institute, Erasmus University Rotterdam, P.O. Box 1738, NL-3000 DR Rotterdam, The Netherlands, e-mail: nibbering@ese.eur.nl 


\section{Introduction}

Econometric models cannot accurately predict events when developers of the models fail to include information about main drivers of the outcomes. The global financial crisis is an example of the failure of models to account for the actual evolution of the real-world economy (Colander et al., 2009). Besides econometric models also surveys of forecasters provide predictions about key economic variables. Although professional forecasters cannot predict one-off events, like natural disasters, they may be quicker in taking into account interpretations of news and various expert opinions than econometric models before they form a final prediction. Fiscal, political, or weather conditions can be reasons for experts to arrive at predictions different from model-based forecasts. According to the amount of attention these surveys receive, they are perceived to contain useful information about the economy (as Ghysels and Wright (2009) note).

In this paper we examine what professional forecasters actually are able to predict. Do they explain movements in economic time series which can also be explained by regular components like a trend or a business-cycle, or also a part of the irregular component, which can hardly be predicted by econometric models and non-experts? To address this question, we decompose 5 key economic variables (GDP, the GDP price index, unemployment, industrial production and housing starts) of the US economy in three components. Subsequently we examine whether panelists of the Survey of Professional Forecasters can explain the variation in the time series due to the different estimated components.

To decompose the economic variables we apply two commonly used methods in the literature to extract trends and business-cycles from time series. First we apply the Baxter and King (1999) low-pass filter which Baxter (1994) uses for the decomposition of exchange rates series into a trend, business-cycle, and irregular component. Second, we perform the same decomposition through a state space model which is studied by Harvey (1985). Since each decomposition relies on different assumptions, we perform both methods and assess whether the results are robust. Next, we regress the forecasts of the professional forecasters on the estimated components in both the spectral analysis and the state space model. We deal with the presence of a unit root in the forecasts and the estimated trend by using the framework of Park and Phillips (1989). To account for two-step 
uncertainty in the standard errors we implement the Murphy and Topel (2002) procedure.

Our results show that the professional forecasters can predict almost all variation in the time series due to the trend and the business-cycle components in the short-run, but explain little or even nothing of the variation in the irregular component. Both approaches to decompose the time series lead to approximately the same results in the forecast regressions. For larger forecast horizons, prediction of the cyclical component becomes worse. The results look very similar if we replace the professional forecasts by simple time series model forecasts. Professional forecasters perform slightly better with respect to root mean squared prediction error than structural time series model, which is commonly used to estimate trends and cycles in time series. The difference is however only significant in a particular sample period. Finally, results suggest that professional forecasters seem to explain the realized values in the current period, which is already published, instead of explaining irregular events in the future.

Although forecast performance is a widely debated topic, we are, to the best of our knowledge, the first to assess forecasts from the perspective of 'what' is predicted instead of 'how good' the actual values are predicted. Hyndman and Koehler (2006) state that "despite two decades of papers on measures of forecast error" the recommended measures still have some fundamental problems. Moreover, all these measures are relative and have to be compared to a benchmark model. By assessing whether a significant amount of variation of the different components of a time series can be explained, no benchmark forecast is needed. Leitch and Ernesttanner (1995) show that conventional forecast evaluation criteria have little to do with the profitability of forecasts, which determines why firms spends millions of dollars to purchase professional forecasts. These firms may believe that experts have information about irregular movements in the future which cannot be predicted by econometric models.

The performance of professional forecasts have been subject to a number of studies. Thomas et al. (1999), Mehra (2002), and Gil-Alana et al. (2012) show that forecast surveys outperform benchmark models for forecasting inflation. These papers focus on the relative strength of expert forecasts in comparison to other forecast methods. In a comprehensive study, Ang et al. (2007) also show that professional forecasters outperform other forecasting methods in predicting inflation 
by means of relative measures and combinations of forecast methods. Instead of focusing on the relative strength of expert forecasts, we question what professional forecasters actually predict. Moreover, where other studies focus only on forecasting inflation, we also consider other key variables of the US economy. Franses et al. (2011) examine forecasts of various Dutch macroeconomic variables and conclude that expert forecasts are more accurate than model-based forecasts. Other papers show limited added value of professionals' forecasts. Franses and Legerstee (2010) show that in general experts are worse than econometric models in forecasting sales at the stock keeping unit level. Isiklar et al. (2006) find that professional forecasts of Consensus Economics do not include all available new information. In a comparison between forecasts of professional forecasters and their long-run expectations, Clements (2015) finds little evidence that the forecasts of the Survey of Professional Forecasters are more accurate than forecasting the trend. Billio et al. (2013) show that the performance trade-off between a white noise model and professional forecasts in predicting returns differs over time. There is also a literature that uses professional forecasts to improve models. For instance, Kozicki and Tinsley (2012) incorporates survey data in a model for inflation to have timely information on structural change, Mertens (2015) estimates trend inflation with the help of survey expectations, and Altug and Çakmaklı (2016) claim superior predictive power of models for inflation incorporating survey expectations.

The outline of this paper is as follows. Section 2 explains the decomposition methods of the economic time series and the forecast regressions of the professional forecasts on the estimated components. Section 3 describes the economic time series and the corresponding forecasts from the Survey of Professional Forecasters, on which we apply the methods. Section 4 discusses the results obtained from the time series decompositions and the forecast regressions. Section 5 provides comparisons between professional and model-based forecasts to provide more insight in the results. We conclude with a discussion in Section 6 .

\section{Methods}

To examine what professional forecasters actually forecast, we decompose the historical values for the predicted time series into three components; a trend, businesscycle, and irregular component. Since most macroeconomic surveys provide sea- 
sonally adjusted data, we consider seasonally adjusted time series and hence do not model the seasonal component. However, we argue that our methodology can easily be extended to seasonally unadjusted data. There are two common methods in the literature for decomposing time series; filters in the frequency domain and state space modeling in the time domain. Since each method relies on different assumptions (Harvey and Trimbur, 2003), we perform both methods and assess whether the results correspond with each other. In Section 2.1, we discuss the filtering of different components from the time series in a spectral analysis. Section 2.2 deals with the trend-cycle decomposition in a state space framework. Finally, Section 2.3 assesses the forecast regression, where we regress the professional forecasts on both the estimated components in the spectral analysis and on the estimated components in the state space framework. The estimated coefficients in these forecast regressions indicate which components can be explained by the professional forecasters.

\subsection{Spectral Analysis}

We consider the model

$$
y_{t}=\mu_{t}+c_{t}+\varepsilon_{t}
$$

where $y_{t}$ is the observed time series, $\mu_{t}$ represents the trend, $c_{t}$ the businesscycle, and $\varepsilon_{t}$ the irregular component. In other words, we have a slow-moving component, an intermediate component, and a high-frequency component. We isolate these different frequency bands by a low-pass filter derived by Baxter and King (1999). They obtain the component time series by applying moving averages to the observed time series. The time series in a specific frequency band can be isolated by choosing the appropriate weights in the moving average.

The filter produces a new time series $x_{t}$ by applying a symmetric moving average to the filtered time series $y_{t}$ :

$$
x_{t}=\sum_{k=-K}^{K} a_{k} y_{t-k},
$$


with weights $a_{k}=a_{-k}$ specified as

$$
\begin{aligned}
& a_{k}=b_{k}+\theta, \\
& b_{k}= \begin{cases}\omega / \pi & \text { if } k=0 \\
\sin (k \omega) /(k \omega) & \text { if } k=1, \ldots, K,\end{cases}
\end{aligned}
$$

where

$$
\theta=\left(1-\sum_{k=-K}^{K} b_{k}\right) /(2 K+1)
$$

is the normalizing constant which ensures that the low-pass filter places unit weight at the zero frequency. We denote the low-pass filter by $L P_{K}(p)$ where $K$ is the lag parameter for which $K=12$ is assessed as appropriate for quarterly data by Baxter and King (1999). This means that we use twelve leads and lags of the data to construct the filter, so three years of observations are lost at the beginning and the end of the sample period. The periodicity $p$ of cycles is a function of the frequency $\omega: p=2 \pi / \omega$. We follow Baxter and King (1999) in the definition of the business-cycle as cyclical components of no less than six quarters and fewer than 32 quarters in duration, and assign all components at lower frequency to the trend and higher frequencies to the irregular component. Thus, the filtered trend equals $L P_{12}(32)$ and the filtered business-cycle $L P_{12}(6)-L P_{12}(32)$. The filtered irregular component equals the original time series $y_{t}$ minus the filtered trend and filtered business-cycle component. Note that the low-pass filter "filters" two-sided estimates for the components which can also be referred to as smoothed estimates of the time series components. It is possible to apply the low-pass filter to seasonally unadjusted data by adding an additional frequency band to the bandpass filter.

Beside the Baxter and King filter there are more filtering methods in the frequency domain which can be used for extracting the trend and the business-cycle component from a time series. For example, Christiano and Fitzgerald (2003) and Pollock (2000) also propose frequency filters suitable for decomposing time series in three components. In our application we will show that these filters provide similar results as the Baxter and King filter. 


\section{$2.2 \quad$ State Space Model}

Although the Baxter and King filter is a simple and effective methodology in extracting trends and cycles from time series, it does not allow for making any statistical inference on the components. Therefore we also estimate the components in a model-based approach, in which we obtain confidence intervals for the estimated component series. Moreover, we can estimate the periodicity of the cycle within the model instead of arbitrarily choosing the frequency bands. However, estimation of the model parameters must be feasible, and also in the time domain we have to make assumptions on the functional form of the model.

A well-known model-based approach in time series decomposition is the state space framework based on the basic structural time series model of Harvey (1990). After including a cyclical component representing the business-cycle, we consider the following model;

$$
y_{t}=\mu_{t}+c_{t}+\varepsilon_{t}, \quad \varepsilon_{t} \sim N\left(0, \sigma_{\varepsilon}^{2}\right),
$$

where $y_{t}$ is the observed time series, $\mu_{t}$ represents the trend, $c_{t}$ the business-cycle, and $\varepsilon_{t}$ the irregular component with variance $\sigma_{\varepsilon}^{2}$. The trend component is specified by the local linear trend model

$$
\begin{aligned}
\mu_{t+1} & =\mu_{t}+\nu_{t}+\xi_{t}, & & \xi_{t} \sim N\left(0, \sigma_{\xi}^{2}\right), \\
\nu_{t+1} & =\nu_{t}+\zeta_{t}, & & \zeta_{t} \sim N\left(0, \sigma_{\zeta}^{2}\right),
\end{aligned}
$$

where $\nu_{t}$ represents the slope of the trend, and $\sigma_{\xi}^{2}$ and $\sigma_{\zeta}^{2}$ are the variances of the shocks. We opt for a smooth stochastic trend specification as in, for example, Durbin and Koopman (2012), by restricting $\sigma_{\xi}^{2}$ to zero. The business-cycle component is represented by the following relations

$$
\begin{array}{llrl}
c_{t+1} & =\rho c_{t} \cos \lambda+\rho c_{t}^{*} \sin \lambda+\kappa_{t}, & & \kappa_{t} \sim N\left(0, \sigma_{\kappa}^{2}\right), \\
c_{t+1}^{*}=-\rho c_{t} \sin \lambda+\rho c_{t}^{*} \cos \lambda+\kappa_{t}^{*}, & & \kappa_{t}^{*} \sim N\left(0, \sigma_{\kappa}^{2}\right),
\end{array}
$$

where the unknown coefficients $\rho, \lambda$, and $\sigma_{\kappa}^{2}$ represent the damping factor, the cyclical frequency, and the cycle error term variance, respectively. The period of the cycle equals $2 \pi / \lambda$ and we impose the restrictions $0<\rho<1$ and $0<\lambda<\pi$. For seasonally unadjusted data we can add a cycle with a seasonal frequency to 
the state space model, to obtain an extra component which captures the seasonal variation.

We estimate the unknown parameters $\left(\sigma_{\varepsilon}^{2}, \sigma_{\xi}^{2}, \sigma_{\zeta}^{2}, \sigma_{\kappa}^{2}, \rho, \lambda\right)$ in a state space framework;

$$
\begin{aligned}
y_{t} & =Z \alpha_{t}+\varepsilon_{t}, & \varepsilon_{t} & \sim N\left(0, \sigma_{\varepsilon}^{2}\right), \\
\alpha_{t+1} & =T \alpha_{t}+\eta_{t}, & & \eta_{t} \sim N(0, Q),
\end{aligned}
$$

where the observation equation relates the observation $y_{t}$ to the unobserved state vector $\alpha_{t}$, which contains the trend and the cycle. This vector is modeled in the state equation. We use Kalman filtering and smoothing to obtain maximum likelihood parameter estimates and estimates for the state vector components (see, e.g., Durbin and Koopman (2012)).

Where the objective of the estimation routine is to minimize the observation noise $\varepsilon_{t}$ relative to the trend and the cycle, we are in this case also interested in the irregular component. So instead of allocating all variance in the time series to the trend and cycle components, the observation noise has to capture the irregular movement. To prevent the variance of the observation noise $\sigma_{\varepsilon}^{2}$ from going to zero, we fix it to the value of the variance of the estimated irregular component in the low-pass filter. ${ }^{1}$ As we show in Section 4.2, our results are robust with respect to alternative values for the variance of the observation noise.

\subsection{Forecast Regression}

Both the spectral analysis and the state space model yield a decomposition of the actual values in the historical time series. From here we investigate how the professional forecasts are related to the components of the historical time series by the regression equation

$$
f_{t+h \mid t}=\beta_{0}+\beta_{1} \hat{\mu}_{t+h \mid T}+\beta_{2} \hat{c}_{t+h \mid T}+\beta_{3} \hat{\varepsilon}_{t+h \mid T}+v_{t+1},
$$

where $f_{t+h \mid t}$ is the professional forecast for $h$ time periods ahead conditional on the information known in time period $t$. The $\hat{\mu}_{t+h \mid T}$ represents the estimated

\footnotetext{
${ }^{1}$ Stock and Watson (1998) develop estimators and confidence intervals for the parameters in a state space model where the maximum likelihood estimator of the variance of the stochastic trend has a large point mass at zero. Our situation is different, as we restrict the variance of the observation noise.
} 
trend, $\hat{c}_{t+h \mid T}$ the estimated business-cycle, and $\hat{\varepsilon}_{t+h \mid T}$ the irregular component. We consider the irregular component, which is constructed as the observed time series from which the estimated trend and cycle is removed, as estimate for the irregular variation in the observed time series. The components are estimated using the series $y_{t}$ for $t=2, \ldots, T$, where each $y_{t}$ contains the observed value just before sending the survey in time period $t+h$. When the professional forecasters perfectly predict the actual values, we have $\hat{\beta}=\left(\hat{\beta}_{0}, \hat{\beta}_{1}, \hat{\beta}_{2}, \hat{\beta}_{3}\right)=(0,1,1,1)$ as the estimated components add up to the actual values. The coefficient $\beta_{0}$ accounts for a potential forecast bias in case the coefficients of the estimated components equal one.

It is good to emphasize that we do not consider the models in (1) and (6) as the true data generating process for the observed time series. The purpose of these models is to estimate the trend and cycle as precisely as possible. The irregular component is what is left over in the actual series after reasonable estimates of the trend and cycle have been removed. The structural time series model (6) imposes that the trend and cycle components are independent. As the trend/cycle estimates follow from filters, the estimated irregular component may be serially correlated as well. The persistence in our estimated irregular components is however very low. We want to address whether, despite the absence of persistence in this component, professional forecasters can possibly predict some of the variation in the irregular component due to their expert information.

As the fitted trend and cycle are estimated using the same data they are correlated (Dungey et al., 2015). Hence, the estimated irregular component may also be correlated with the trend and cycle. This is however not a problem as the OLS estimator in (13) corrects for the correlation between the components.

Since many economic time series exhibit trending behavior, we expect a stochastic trend in the series of professional forecasts. We explicitly model a unit root in the local linear trend model in the state space framework. Unless professional forecasters have done a very poor job, there is a long-run relationship between the stochastic trend of the economic time series and the predicted values for this variable. So, we expect that the forecasts and the estimated trend are cointegrated. To examine this conjecture, we test in our empirical analysis for cointegration between the professional forecasts and the estimated trend with the Engle and Granger (1987) residual-based cointegration test.

In case of cointegration, we have in (13) a regression with cointegrated vari- 
ables $f$ and $\hat{\mu}$ together with the $I(0)$ variables $\hat{c}$ and $\hat{\varepsilon}$. Park and Phillips (1989) show that in this situation the parameters can be consistently estimated with ordinary least squares. They also provide asymptotically chi-squared distributed Wald test statistics for inference on the estimated parameters (Park and Phillips, 1989, p. 108). We test whether the estimated parameters are individually equal to the values in a perfect forecast. Moreover, we test the null hypothesis of perfectly predicted values, that is $\beta=(0,1,1,1)$.

The standard errors of the estimated coefficients in (13) do not account for the uncertainty in the regressors. Due to the fact that the regressors are estimates we may encounter heteroskedasticity in the residuals. Therefore we opt for White standard errors when the components are estimated in the spectral analysis (White, 1980). One of the benefits of the state space model is that here we do obtain estimates of the uncertainty in the model parameters. We can exploit the estimated parameter uncertainty in the state space framework by implementing the Murphy and Topel (2002) procedure for computing two-step standard errors. Adjusting the standard covariance matrix of the forecast regression parameters with the state space model parameter covariance matrix results in asymptotically correct standard errors.

It might be appealing to simultaneously estimate the historical time series components using (6)-(10) and the forecast regression coefficients in (13) by including the forecast regression in the state space framework. In this way we directly estimate standard errors for the estimated forecast regression coefficients, without the concern that we ignore the uncertainty in the estimated components. However, this approach allows the forecasts to influence the estimates of the components of the historical time series, which leads to incorrect inference. For this reason we do not consider this simultaneous set-up.

Finally, we want to stress that we use regression (13) to infer the correlations between the components of the historical time series and the predictions. We do not assume that forecasters really use the estimated components to arrive at their predictions, or make any other assumption about the generating process of predictions. Hence, we do not intend to make causality statements. 


\section{Data}

We apply the methods of Section 2 to the well-documented and open database of the Survey of Professional Forecasters. We focus on key variables of the US economy which are available over a long period. We consider real-time data of nominal GDP, GDP price index, unemployment, industrial production index, and housing starts. The forecasts for the Survey of Professional Forecasters are provided by the Federal Reserve Bank of Philadelphia.

To determine the information sets of the forecasters at the moment of providing the forecasts, we consider the timing of the survey. The quarterly survey, formerly conducted by the American Statistical Association and the National Bureau of Economic Research, began in the last quarter of 1968 and was taken over by the Philadelphia Fed in the second quarter of 1990. We collect data up to the second quarter of 2014. Table 1 shows all relevant information concerning the timing of the survey since it is conducted by the Philadelphia Fed. There is still some uncertainty about the timing before mid 1990 but the Philadelphia Fed assumes that it is similar to the timing afterwards. Based on this information we suppose that all panelists in the survey are informed about the actual values of the predicted variables up to and including the previous quarter. We use the same information set for constructing the model-based forecasts. Although the exact day of the month on which forecasters have to submit their predictions differs over the surveys, our results in Section 4.2 turn out to be robust to the differences in timing and to the takeover of the survey by the Philadelphia Fed.

Since the individual forecasters in the survey have limited histories of responses and forecasters may switch identification numbers, we mainly use time series of mean forecasts for the level of economic variables for which the data set includes observations over the whole survey period. The forecasts of the survey panelists are averaged in each time period. Beside the forecasts, the database of the Survey of Professional Forecasters also provides the real-time quarterly historical values corresponding to the predicted series. These historical values are included in the information sets of the panelists, before they receive the survey for the next quarter. Therefore, the Real-Time Data Set for Macroeconomists (Croushore and Stark, 2001) could contain different values when there is a new release of the data after the survey is send but before the deadline for returning it. We assess the predic- 
Table 1: Timing Survey of Professional Forecasters 1990:Q3 to present

\begin{tabular}{lllll}
\hline Survey & $\begin{array}{l}\text { Questionnaires } \\
\text { Sent }\end{array}$ & $\begin{array}{l}\text { Last Quarter } \\
\text { in Panelists' } \\
\text { Information Sets }\end{array}$ & $\begin{array}{l}\text { Deadline } \\
\text { Submissions }\end{array}$ & $\begin{array}{l}\text { Results } \\
\text { Released }\end{array}$ \\
\hline Q1 & End of January & Q4 & Middle of February & Late February \\
Q2 & End of April & Q1 & Middle of May & Late May \\
Q3 & End of July & Q2 & Middle of August & Late August \\
Q4 & End of October & Q3 & Middle of November & Late November \\
\hline
\end{tabular}

The first three columns of this table provide the dates on which the survey for the current quarter is sent to the panelists and the last quarter of the series of actual historical values that is in the panelists' information set at this moment. The last two columns indicate when the forecasts for the current quarter must be submitted and when the results of these forecasts are released.

tive performance against the time series decompositions of the real-time historical values provided by the survey.

Table 2 lists the series, which are all seasonally adjusted. The unemployment rate, index of industrial production, and housing starts are averaged over the underlying monthly levels. The base year for the GDP price index and the index of industrial production changed several times in the considered sample period. We rescale the time series to base year 1958 in case of the GDP price index and 1957-1959 in case of the index of industrial production. All base year changes, temporal aggregation, and a detailed explanation of the Survey of Professional Forecasters can be found in the documentation of the Federal Reserve Bank of Philadelphia. $^{2}$

In this paper we consider the logarithm of all historical time series and forecasts multiplied by one hundred. Figure 1 shows these key variables of the US economy. The solid line corresponds to the historical time series and the dashed dotted line to the difference between the historical values and the predictions by the Survey of Professional Forecasters. We recognize an upward trend in nominal GDP, GDP price index, and industrial production index. The latter two also show

\footnotetext{
${ }^{2}$ http://www.philadelphiafed.org/research-and-data/real-time-center/ survey-of-professional-forecasters/spf-documentation.pdf
} 
Table 2: Variables Description

\begin{tabular}{ll}
\hline Variable & Description \\
\hline NGDP & Annual rate nominal GDP in billion dollars. \\
& Prior to 1992 nominal GNP. \\
PGDP & GDP price index with varying base years. \\
& Prior to 1996 GDP implicit deflator and prior to 1992 GNP deflator. \\
UNEMP & Unemployment rate in percentage points. \\
INDPROD & Index of industrial production with varying base years. \\
HOUSING & Annual rate housing starts in millions. \\
\hline
\end{tabular}

This table provides a short summary of each variable. All variables are seasonally adjusted.

some cyclical movements. From unemployment and housing we cannot directly identify a trend, but we see clear cyclical patterns in these series.

Table 3 shows the forecast bias for each variable computed as the average over the difference between the predictions of the survey of professional forecasters and the real-time historical values over different forecast horizons. A positive bias means that the professional forecasters on average overestimate the actual values. For the NGPD and PGDP series, the bias is almost always negative but small compared to the standard deviation. For the other series the bias is in most of the cases positive.

\section{Results}

In this section we discuss the results of the analysis of the predictions of the Survey of Professional Forecasters. First, we consider the decomposition of the actual time series based on both the frequency and time domain analysis. Second, we examine the relation between the professional forecasts and the estimated components. We first consider one-step ahead predications based on the mean of the professional forecasts, followed by the same analysis based on individual forecasts. We end this section by considering multiple-step ahead forecasts. 
Table 3: Forecast Bias Estimates

\begin{tabular}{rrrrrr}
\hline \hline horizon & 1 & 2 & 3 & 4 & 5 \\
\hline \multirow{2}{*}{ NGDP } & -0.165 & -0.277 & -0.324 & -0.332 & -0.170 \\
& $(0.750)$ & $(1.252)$ & $(1.709)$ & $(2.144)$ & $(2.590)$ \\
PGDP & -0.012 & -0.025 & -0.024 & -0.025 & 0.276 \\
& $(0.446)$ & $(0.710)$ & $(0.997)$ & $(1.327)$ & $(1.241)$ \\
UNEMP & 0.799 & 1.112 & 0.787 & 0.111 & -0.110 \\
& $(2.438)$ & $(5.587)$ & $(8.438)$ & $(11.434)$ & $(13.917)$ \\
INDPROD & -0.039 & 0.122 & 0.369 & 0.704 & 1.031 \\
& $(1.284)$ & $(2.425)$ & $(3.493)$ & $(4.406)$ & $(5.080)$ \\
HOUSING & -0.391 & 1.059 & 3.141 & 5.262 & 6.628 \\
& $(7.085)$ & $(12.192)$ & $(16.147)$ & $(19.948)$ & $(23.053)$ \\
\hline \hline
\end{tabular}

This table shows the forecast bias and the standard deviation in parentheses for each variable over different horizons. The bias is computed as the average over the difference between the predictions of the Survey of Professional Forecasters and the actual historical values. A positive bias means that the forecasters on average overestimate the actual values. Due to missing values, the estimation sample starts at 1974Q4 for $h=5$.

\subsection{Time Series Decomposition}

Figure 2 shows nominal GDP decomposed in a trend, a cycle, and an irregular component by the low-pass filters and the state space model. For all components the two time series follow roughly the same pattern. The fact that the two methods, which rely on different assumptions, result in approximately the same decomposition indicates that the estimated decompositions are reliable. We conclude the same for the other time series, that is GDP price index, unemployment, industrial production index, and housing starts, for which Figure A1 up to Figure A4 can be found in Appendix A.

Table 4 shows the state space model parameter estimates. Almost all parameter estimates are significant. The estimated period of the cycle in GDP equals nineteen quarters, which lies in the business-cycle period interval defined by Baxter and King. Except for housing starts (33 quarters), this is also the case for all other 
Table 4: State Space Model Parameter Estimates

\begin{tabular}{ccccccc}
\hline \hline & \multicolumn{5}{c}{ Estimate (Std. error) } & Implied \\
\cline { 2 - 6 } & $\sigma_{\varepsilon}$ & $\sigma_{\zeta}$ & $\sigma_{\kappa}$ & $\lambda$ & $\rho$ & Cycle \\
\hline \multirow{2}{*}{ NGDP } & 0.489 & 0.142 & 0.577 & 0.330 & 0.910 & 19 \\
& & $(0.055)$ & $(0.091)$ & $(0.083)$ & $(0.034)$ & \\
PGDP & 0.241 & 0.131 & 0.218 & 0.314 & 0.954 & 20 \\
& & $(0.030)$ & $(0.043)$ & $(0.035)$ & $(0.020)$ & \\
UNEMP & 2.152 & 0.360 & 3.791 & 0.218 & 0.978 & 29 \\
& & $(0.194)$ & $(0.298)$ & $(0.019)$ & $(0.013)$ & \\
INDPROD & 0.908 & 0.070 & 1.454 & 0.250 & 0.948 & 25 \\
& & $(0.037)$ & $(0.116)$ & $(0.029)$ & $(0.018)$ & \\
HOUSING & 5.241 & 0.309 & 6.721 & 0.188 & 0.965 & 33 \\
& & $(0.181)$ & $(0.688)$ & $(0.028)$ & $(0.016)$ & \\
\hline \hline
\end{tabular}

This table shows the parameter estimates in the state space model where the variance of the observation noise $\sigma_{\varepsilon}^{2}$ is fixed to the variance of the irregular component estimated by the low-pass filter. The $\sigma_{\varepsilon}$ represents the standard deviation of the observation noise, $\sigma_{\zeta}$ the second order trend error term standard deviation, $\sigma_{\kappa}$ the cycle error term standard deviation, $\lambda$ the cyclical frequency, and $\rho$ the damping factor. The standard errors of the estimates are reported in parentheses. The last column presents the period of the cycle (in quarters), implied by the $\lambda$ estimate.

variables.

\subsection{Forecast Regression}

As discussed in Section 2.3, for correct inference of the forecast regression parameters in (13) the forecasts should be cointegrated with the estimated trend. Table 5 shows the Engle-Granger cointegration test results on both the estimated trend in the spectral analysis as the estimated trend in the state space model for the one-step ahead forecasts. The null hypothesis of no cointegration is rejected at a $5 \%$ significance level in all cases, except for the trend in the GDP price index resulting from the spectral analysis. Hence, we have to be more careful interpreting the results of the forecast regression for this variable. For the other four variables we can straightforwardly use the Park and Phillips (1989) test statistics. 
Table 5: Cointegration Tests Forecast and Trend Time Series

\begin{tabular}{rrrr|rrr}
\hline \hline & \multicolumn{3}{c}{ Spectral Analysis } & \multicolumn{3}{c}{ State Space Model } \\
& $\tau$-stat. & lags & $p$-value & $\tau$-stat. & lags & $p$-value \\
\hline NGDP & -5.806 & 1 & 0.000 & -6.136 & 1 & 0.000 \\
PGDP & -2.973 & 0 & 0.123 & -3.941 & 0 & 0.011 \\
UNEMP & -5.538 & 1 & 0.000 & -4.397 & 1 & 0.003 \\
INDPROD & -5.978 & 1 & 0.000 & -4.814 & 1 & 0.001 \\
HOUSING & -3.977 & 2 & 0.010 & -3.791 & 1 & 0.017 \\
\hline \hline
\end{tabular}

This table shows the Engle-Granger residual-based cointegration test of the null hypothesis of no cointegration against the alternative of cointegration. The professional one-step ahead forecast is the dependent variable and an intercept is included. The MacKinnon (1996) $p$-values are reported and the lag length is specified as the number of lagged differences in the test equation determined by the Schwarz criterion. The first four columns show the results based on the estimated trend in the spectral analysis and the last three columns the results based on the estimated trend in the state space model.

We include the estimated components in the forecast regression equation (13) with $h=1$ to examine how the professional one-step ahead forecasts are related to the different components. Table 6 shows the results based on the estimated components in the spectral analysis and Table 7 shows the results based on the state space model. Due to the lag parameter in the spectral analysis, the filtered series start after twelve quarters from the beginning of the sample period and end twelve quarters before the end of the sample period. To make the results comparable we also exclude these observations from the estimated series in the state space framework, which results in a sample period from the last quarter of 1971 to the second quarter of 2011. Table B1 in Appendix B reports the results of the spectral analysis based on the Christiano-Fitzgerald and the Butterworth filter. Since the outcomes are very similar, we only discuss the results based on the Baxter and King decomposition here.

Tables 6 and 7 show the estimated coefficients for each component with the standard errors in parentheses and the Wald test statistic on the null hypothesis 
that the coefficient is equal to the weight expected in a perfect forecast. That is, the intercept is tested against zero and the components against one. These Wald test statistics are asymptotically chi-squared distributed with critical value 3.842 at the $5 \%$ significance level. The asterisks indicate whether a coefficient significantly differs from the value that is expected in a perfect forecast. The first six columns of each table show the forecast regression for each variable with intercept, and the last four columns the results without intercept $\left(\beta_{0}=0\right)$.

The first six columns of Table 6 show that the trend and cycle components receive a weight close to one. Although some of these estimates significantly differ from one due to the small standard errors, we can say that the professional forecasters can predict most of the variation caused by a trend and a business-cycle. However, the parameter estimates corresponding to the irregular component differ significantly from one while having large standard errors. Moreover, some of the weights of the irregular components do significantly differ from zero, which means that the professional forecasters still seem to capture a bit of the irregular movements in the time series.

When the weights of the estimated components equal one, the estimated intercept accounts for a potential bias in the level of the forecasts. Because most variables are on average underestimated by the professional forecasters, we estimate in most cases a negative intercept. The estimated weights of the components do not change much when we do not include an intercept; the estimated weights for the trend and the cycle are close to one and the weights for the irregular component are similar as before (last four columns of Table 6). Moreover, unreported results show that fixing the coefficients of the trend and cycle components to one, barely changes the results with respect to the estimated weights of the irregular components.

Table 7 shows the results based on the estimated components in the state space model. We find almost the same results. The estimated weights for the trend and cycle components are again close to one. However, it is remarkable that in case of the state space analysis all estimated weights for the irregular components are negative and in about half of the cases even significantly different from zero. The Wald test on the null hypothesis that the professional forecasters perfectly predict is again rejected for all variables with $p$-values equal to 0.000 . Some of the estimated weights for the trend and cycle components differ significantly from 
Table 6: Forecast Regressions $(h=1)$ Based On Spectral Analysis

\begin{tabular}{|c|c|c|c|c|c|c|c|}
\hline & \multicolumn{4}{|c|}{ Estimate (Std. error) } & \multicolumn{3}{|c|}{ Estimate (Std. error) } \\
\hline & intercept & trend & cycle & irreg. & trend & cycle & irreg. \\
\hline NGDP & $\begin{array}{c}-1.178 \\
(0.620) \\
3.613\end{array}$ & $\begin{array}{c}1.001 \\
(0.001) \\
2.752\end{array}$ & $\begin{array}{c}0.954 \\
(0.037) \\
1.505\end{array}$ & $\begin{array}{c}0.249^{*} \\
(0.149) \\
25.494\end{array}$ & $\begin{array}{c}1.000^{*} \\
(0.000) \\
10.051\end{array}$ & $\begin{array}{c}0.959 \\
(0.038) \\
1.150\end{array}$ & $\begin{array}{c}0.248^{*} \\
(0.154) \\
23.802\end{array}$ \\
\hline PGDP & $\begin{array}{c}-0.197 \\
(0.505) \\
0.153\end{array}$ & $\begin{array}{c}1.000 \\
(0.001) \\
0.120\end{array}$ & $\begin{array}{c}0.990 \\
(0.037) \\
0.080\end{array}$ & $\begin{array}{c}-0.132^{*} \\
(0.173) \\
42.95\end{array}$ & $\begin{array}{c}1.000 \\
(0.000) \\
0.839\end{array}$ & $\begin{array}{c}0.992 \\
(0.039) \\
0.045\end{array}$ & $\begin{array}{c}-0.133^{*} \\
(0.174) \\
42.302\end{array}$ \\
\hline UNEMP & $\begin{array}{c}1.318 \\
(1.960) \\
0.452\end{array}$ & $\begin{array}{c}0.997 \\
(0.011) \\
0.067\end{array}$ & $\begin{array}{c}0.949^{*} \\
(0.016) \\
9.966\end{array}$ & $\begin{array}{c}0.581^{*} \\
(0.104) \\
16.208\end{array}$ & $\begin{array}{c}1.004^{*} \\
(0.001) \\
18.975\end{array}$ & $\begin{array}{c}0.945^{*} \\
(0.015) \\
13.982\end{array}$ & $\begin{array}{c}0.587^{*} \\
(0.102) \\
16.418\end{array}$ \\
\hline INDPROD & $\begin{array}{c}-3.491 \\
(1.936) \\
3.251\end{array}$ & $\begin{array}{c}1.006 \\
(0.003) \\
3.194\end{array}$ & $\begin{array}{c}0.938^{*} \\
(0.030) \\
4.386\end{array}$ & $\begin{array}{c}0.441^{*} \\
(0.168) \\
11.122\end{array}$ & $\begin{array}{c}1.000 \\
(0.000) \\
0.102\end{array}$ & $\begin{array}{c}0.939^{*} \\
(0.030) \\
4.246\end{array}$ & $\begin{array}{c}0.440^{*} \\
(0.166) \\
11.401\end{array}$ \\
\hline HOUSING & $\begin{array}{c}2.555^{*} \\
(0.880) \\
8.423\end{array}$ & $\begin{array}{c}0.919^{*} \\
(0.022) \\
13.960\end{array}$ & $\begin{array}{c}0.888^{*} \\
(0.038) \\
8.832\end{array}$ & $\begin{array}{c}0.239^{*} \\
(0.119) \\
40.781\end{array}$ & $\begin{array}{c}0.973^{*} \\
(0.010) \\
6.847\end{array}$ & $\begin{array}{c}0.847^{*} \\
(0.036) \\
18.427\end{array}$ & $\begin{array}{c}0.252^{*} \\
(0.119) \\
39.817\end{array}$ \\
\hline
\end{tabular}

This table shows the parameter estimates in forecast regression (13) of the professional forecasts on the low-pass filter decomposition, with and without intercept. White standard errors are reported in parentheses together with Wald test statistics on the null hypothesis that the coefficient is equal to the weight expected in a perfect forecast. An asterisk $(*)$ denotes that the coefficient significantly differs from the weight expected in a perfect forecast at the $5 \%$ significance level.

one, for example GDP price index and housing starts.

One could argue that the results in Tables 6 and 7 can be different before the Philadelphia Fed took over the survey compared to the period thereafter. However, including a dummy for the period after the take-over is almost never significant on a five percent level and does not significantly change the estimated coefficients of the components, and is therefore omitted from the reported forecast regressions. We also account for the varying calender dates for the survey deadline as well for the release dates of the survey results. These dates are documented from the moment The Fed took over the survey. For this sample period we include a dummy indicating whether the amount of days between the last release and the next deadline is above or below the median. Again we do not find significant 
Table 7: Forecast Regressions $(h=1)$ Based On State Space Model

\begin{tabular}{|c|c|c|c|c|c|c|c|}
\hline & \multicolumn{4}{|c|}{ Estimate (Std. error) } & \multicolumn{3}{|c|}{ Estimate (Std. error) } \\
\hline & intercept & trend & cycle & irreg. & trend & cycle & irreg. \\
\hline NGDP & $\begin{array}{c}-1.242^{*} \\
(0.553) \\
5.049\end{array}$ & $\begin{array}{c}1.001 \\
(0.001) \\
3.794\end{array}$ & $\begin{array}{c}1.063 \\
(0.044) \\
2.009\end{array}$ & $\begin{array}{c}-0.596^{*} \\
(0.194) \\
67.910\end{array}$ & $\begin{array}{c}1.000^{*} \\
(0.000) \\
10.242\end{array}$ & $\begin{array}{c}1.061 \\
(0.045) \\
1.861\end{array}$ & $\begin{array}{c}-0.587^{*} \\
(0.196) \\
65.503\end{array}$ \\
\hline PGDP & $\begin{array}{c}-0.316 \\
(0.387) \\
0.666\end{array}$ & $\begin{array}{c}1.001 \\
(0.001) \\
0.627\end{array}$ & $\begin{array}{c}1.096^{*} \\
(0.042) \\
5.242\end{array}$ & $\begin{array}{c}-0.804^{*} \\
(0.171) \\
111.429\end{array}$ & $\begin{array}{c}1.000 \\
(0.000) \\
0.100\end{array}$ & $\begin{array}{c}1.100^{*} \\
(0.042) \\
5.757\end{array}$ & $\begin{array}{c}-0.805^{*} \\
(0.171) \\
111.773\end{array}$ \\
\hline UNEMP & $\begin{array}{c}0.015 \\
(2.082) \\
0.000\end{array}$ & $\begin{array}{c}1.004 \\
(0.011) \\
0.145\end{array}$ & $\begin{array}{c}0.980 \\
(0.011) \\
3.073\end{array}$ & $\begin{array}{c}-0.024^{*} \\
(0.190) \\
29.212\end{array}$ & $\begin{array}{c}1.004^{*} \\
(0.001) \\
21.326\end{array}$ & $\begin{array}{c}0.980 \\
(0.011) \\
3.139\end{array}$ & $\begin{array}{c}-0.024^{*} \\
(0.189) \\
29.413\end{array}$ \\
\hline INDPROD & $\begin{array}{c}-3.708^{*} \\
(1.689) \\
4.821\end{array}$ & $\begin{array}{c}1.006^{*} \\
(0.003) \\
4.724\end{array}$ & $\begin{array}{c}0.989 \\
(0.020) \\
0.300\end{array}$ & $\begin{array}{c}-0.443^{*} \\
(0.229) \\
39.817\end{array}$ & $\begin{array}{c}0.999 \\
(0.000) \\
0.126\end{array}$ & $\begin{array}{c}0.988 \\
(0.021) \\
0.362\end{array}$ & $\begin{array}{c}-0.436^{*} \\
(0.231) \\
38.506\end{array}$ \\
\hline HOUSING & $\begin{array}{c}4.520^{*} \\
(1.240) \\
13.292\end{array}$ & $\begin{array}{c}0.866^{*} \\
(0.032) \\
17.822\end{array}$ & $\begin{array}{c}0.971 \\
(0.020) \\
2.086\end{array}$ & $\begin{array}{c}-0.381^{*} \\
(0.136) \\
103.030\end{array}$ & $\begin{array}{c}0.975^{*} \\
(0.011) \\
5.243\end{array}$ & $\begin{array}{c}0.939 * \\
(0.018) \\
10.927\end{array}$ & $\begin{array}{c}-0.340^{*} \\
(0.141) \\
90.524\end{array}$ \\
\hline
\end{tabular}

This table shows the parameter estimates in forecast regression (13) of the professional forecasts on the state space model decomposition, with and without intercept. Standard errors are reported in parentheses together with Wald test statistics on the null hypothesis that the coefficient is equal to the weight expected in a perfect forecast. An asterisk $(*)$ denotes that the coefficient significantly differs from the weight expected in a perfect forecast at the five percent significance level.

estimates and hence we decide to omit this dummy. To make sure that our results are robust against definition changes, we also perform the analysis of Table 6 on the first differences of the series, where the first differences are constructed using the vintages in the real-time dataset. Appendix $\mathrm{C}$ shows the results. We find that not all the weights of the business-cycle are as close to one as we found for the level data, but the weights of the irregular components are again significantly different from one.

Where we reported the White standard errors and corresponding Wald statistics in case of the components estimated in the spectral analysis in Table 6, in Table 7 ordinary standard errors and Wald statistics are reported. These standard errors do not take into account that the regressors are estimates. Since we 
obtain an estimated covariance matrix of the estimated parameters in the state space framework, we can adjust the ordinary standard errors for the uncertainty in the regressors. Table 8 shows the effect of the uncertainty in the estimated components in the state space model on the results of the forecast regression by reporting the two-step standard errors and corresponding Wald statistics.

The second column of Table 8 shows that the standard errors of the intercepts are now even larger. However, the forecast bias for nominal GDP, industrial production index, and housing starts is still significantly different from zero. Where the weights for the trend and cycle components of housing starts significantly differ from one in case of ordinary standard errors, they do not significantly differ from one when we do not include an intercept and account for uncertainty in the estimated components. The weights of the irregular components are still significantly different from one. It remains remarkable that all estimated weights for the irregular components are negative and that still some of these effects are significantly different from zero. The forecast regressions in the last four columns still have a few trend and cycle coefficients significantly different from one due to small standard errors, for example, for nominal GDP, GDP price index, and unemployment. In general, the conclusions do not change much when we account for two-step uncertainty. The Survey of Professional Forecasters can predict one-step ahead almost all variation in the time series due to a trend and a business-cycle, but predict little of the variation caused by the irregular component.

\subsection{Individual Forecasts Analysis}

As discussed in Section 3, it is difficult to analyse the performance of individual forecasters in the survey, since they have limited histories of responses and forecasters may switch identification numbers. However, we can analyze the individual predictions by pooling them all in one forecast regression. Table 9 shows the results of a forecast regression on all individual forecasts, that is all forecasts over the sample period without averaging over the forecasts from the different panelists in each time period.

We find that the weights corresponding to the trend and the cycle are also close to one when we consider all individual forecasts, instead of the mean of the survey. The estimated parameter of the irregular component is in most cases closer 
Table 8: Forecast Regressions $(h=1)$ With Two-Step Standard Errors

\begin{tabular}{|c|c|c|c|c|c|c|c|}
\hline & \multicolumn{4}{|c|}{ Estimate (Std. error) } & \multicolumn{3}{|c|}{ Estimate (Std. error) } \\
\hline & intercept & trend & cycle & irreg. & trend & cycle & irreg. \\
\hline NGDP & $\begin{array}{c}-1.242^{*} \\
(0.553) \\
5.048\end{array}$ & $\begin{array}{c}1.001 \\
(0.001) \\
3.793\end{array}$ & $\begin{array}{c}1.063 \\
(0.046) \\
1.858\end{array}$ & $\begin{array}{c}-0.596^{*} \\
(0.232) \\
47.390\end{array}$ & $\begin{array}{c}1.000^{*} \\
(0.000) \\
10.241\end{array}$ & $\begin{array}{c}1.061 \\
(0.047) \\
1.725\end{array}$ & $\begin{array}{c}-0.587^{*} \\
(0.233) \\
46.237\end{array}$ \\
\hline PGDP & $\begin{array}{c}-0.316 \\
(0.387) \\
0.666\end{array}$ & $\begin{array}{c}1.001 \\
(0.001) \\
0.627\end{array}$ & $\begin{array}{c}1.096^{*} \\
(0.045) \\
4.650\end{array}$ & $\begin{array}{c}-0.804^{*} \\
(0.192) \\
88.747\end{array}$ & $\begin{array}{c}1.000 \\
(0.000) \\
0.100\end{array}$ & $\begin{array}{c}1.100^{*} \\
(0.044) \\
5.037\end{array}$ & $\begin{array}{c}-0.805^{*} \\
(0.192) \\
88.822\end{array}$ \\
\hline UNEMP & $\begin{array}{c}0.015 \\
(2.098) \\
0.000\end{array}$ & $\begin{array}{c}1.004 \\
(0.012) \\
0.143\end{array}$ & $\begin{array}{c}0.980 \\
(0.012) \\
2.903\end{array}$ & $\begin{array}{c}-0.024^{*} \\
(0.212) \\
23.428\end{array}$ & $\begin{array}{c}1.004^{*} \\
(0.001) \\
21.264\end{array}$ & $\begin{array}{c}0.980 \\
(0.011) \\
2.958\end{array}$ & $\begin{array}{c}-0.024^{*} \\
(0.211) \\
23.539\end{array}$ \\
\hline INDPROD & $\begin{array}{c}-3.708^{*} \\
(1.689) \\
4.818\end{array}$ & $\begin{array}{c}1.006^{*} \\
(0.003) \\
4.722\end{array}$ & $\begin{array}{c}0.989 \\
(0.02) \\
0.298\end{array}$ & $\begin{array}{c}-0.443^{*} \\
(0.261) \\
30.571\end{array}$ & $\begin{array}{c}1.000 \\
(0.000) \\
0.126\end{array}$ & $\begin{array}{c}0.988 \\
(0.021) \\
0.359\end{array}$ & $\begin{array}{c}-0.436^{*} \\
(0.263) \\
29.823\end{array}$ \\
\hline HOUSING & $\begin{array}{c}4.520^{*} \\
(1.719) \\
6.917\end{array}$ & $\begin{array}{c}0.866^{*} \\
(0.045) \\
8.827\end{array}$ & $\begin{array}{c}0.971 \\
(0.044) \\
0.428\end{array}$ & $\begin{array}{c}-0.381^{*} \\
(0.146) \\
88.956\end{array}$ & $\begin{array}{c}0.975 \\
(0.013) \\
3.669\end{array}$ & $\begin{array}{c}0.939 \\
(0.044) \\
1.902\end{array}$ & $\begin{array}{c}-0.340^{*} \\
(0.152) \\
77.655\end{array}$ \\
\hline
\end{tabular}

This table shows the parameter estimates in forecast regression (13) of the professional forecasts on the state space model decomposition, with and without intercept. Standard errors and Wald test statistics account for two-step uncertainty and are computed based on the Murphy and Topel (2002) procedure. Standard errors are reported in parentheses together with Wald test statistics on the null hypothesis that the coefficient is equal to the weight expected in a perfect forecast. An asterisk (*) denotes that the coefficient significantly differs from the weight expected in a perfect forecast at the five percent significance level.

to zero than to one. Since the regressions include a large number of observations (5784) the standard errors become small and almost every weight is significantly different from the weight in a perfect forecast on a five percent significance level. ${ }^{3}$ In sum, the findings are in line with the results based on the mean of the Survey of Professional Forecasters.

\footnotetext{
${ }^{3}$ Unreported results show that a weighted regression where we weight with the number of forecasters to account for time variation in the number of forecasters produces similar results. Results can be obtained from the authors upon request.
} 
Table 9: Forecast Regressions $(h=1)$ Based On Individual Forecasts

\begin{tabular}{|c|c|c|c|c|c|c|c|}
\hline & \multicolumn{4}{|c|}{ Estimate (Std. error) } & \multicolumn{3}{|c|}{ Estimate (Std. error) } \\
\hline & intercept & trend & cycle & irreg. & trend & cycle & irreg. \\
\hline NGDP & $\begin{array}{c}-1.213^{*} \\
(0.113)\end{array}$ & $\begin{array}{c}1.001^{*} \\
(0.000)\end{array}$ & $\begin{array}{c}0.939^{*} \\
(0.008)\end{array}$ & $\begin{array}{c}0.253^{*} \\
(0.027)\end{array}$ & $\begin{array}{c}1.000^{*} \\
(0.000)\end{array}$ & $\begin{array}{c}0.949^{*} \\
(0.008)\end{array}$ & $\begin{array}{c}0.248^{*} \\
(0.028)\end{array}$ \\
\hline PGDP & $\begin{array}{r}-21.752^{*} \\
(0.136)\end{array}$ & $\begin{array}{c}1.042^{*} \\
(0.000)\end{array}$ & $\begin{array}{c}0.745^{*} \\
(0.010)\end{array}$ & $\begin{array}{c}0.055^{*} \\
(0.042)\end{array}$ & $\begin{array}{c}1.005^{*} \\
(0.000)\end{array}$ & $\begin{array}{c}1.135^{*} \\
(0.027)\end{array}$ & $\begin{array}{r}-0.175^{*} \\
(0.107)\end{array}$ \\
\hline UNEMP & $\begin{array}{c}1.529^{*} \\
(0.464)\end{array}$ & $\begin{array}{c}0.995 \\
(0.003)\end{array}$ & $\begin{array}{c}0.952^{*} \\
(0.004)\end{array}$ & $\begin{array}{c}0.628^{*} \\
(0.026)\end{array}$ & $\begin{array}{c}1.004^{*} \\
(0.000)\end{array}$ & $\begin{array}{c}0.947^{*} \\
(0.004)\end{array}$ & $\begin{array}{c}0.635^{*} \\
(0.025)\end{array}$ \\
\hline INDPROD & $\begin{array}{r}-28.892^{*} \\
(0.371)\end{array}$ & $\begin{array}{c}1.054^{*} \\
(0.001)\end{array}$ & $\begin{array}{c}0.929^{*} \\
(0.006)\end{array}$ & $\begin{array}{c}0.448^{*} \\
(0.033)\end{array}$ & $\begin{array}{c}1.003^{*} \\
(0.000)\end{array}$ & $\begin{array}{c}0.944^{*} \\
(0.009)\end{array}$ & $\begin{array}{c}0.426^{*} \\
(0.039)\end{array}$ \\
\hline HOUSING & $\begin{array}{c}2.298^{*} \\
(0.240)\end{array}$ & $\begin{array}{c}0.922^{*} \\
(0.006)\end{array}$ & $\begin{array}{c}0.888^{*} \\
(0.009)\end{array}$ & $\begin{array}{c}0.257^{*} \\
(0.027)\end{array}$ & $\begin{array}{c}0.970^{*} \\
(0.002)\end{array}$ & $\begin{array}{c}0.855^{*} \\
(0.008)\end{array}$ & $\begin{array}{c}0.268^{*} \\
(0.026)\end{array}$ \\
\hline
\end{tabular}

This table shows the parameter estimates in forecast regression (13), of the professional forecasts on the low-pass filter decomposition, with and without intercept. The regressions include all 5784 individual forecasts over the sample period without averaging over the forecasts from the different panelists in each time period. For additional information, see the note following Table 6 .

\subsection{Multi-step-ahead Forecasts}

So far, our results are based on one-step-ahead predictions of the Survey of Professional Forecasters. To examine whether our findings also hold for multi-step-ahead forecasts, we perform the forecast regressions for different forecast horizons. The Survey of Professional Forecasters provides forecasts up to five quarters ahead.

Table 10 shows the results of the forecast regressions for $h=5$ based on spectral analysis. Appendix D shows the results for $h=2, \ldots, 4$. We find that for all forecast horizons, the trend component receives a weight close to one and the weights corresponding to the irregular component are closer to zero than to one. The parameter estimates corresponding to the cycle decrease with the forecast horizon, and the forecast bias increases in the forecast horizon. In sum, we find that the professional forecasters are able to predict the trend over a longer horizon, but the forecasters are less able to produce unbiased forecasts and capture variation in the business-cycle when the forecast horizon increases. 
Table 10: Forecast Regressions Based On Spectral Analysis for $h=5$

\begin{tabular}{|c|c|c|c|c|c|c|c|}
\hline & \multicolumn{4}{|c|}{ Estimate (Std. error) } & \multicolumn{3}{|c|}{ Estimate (Std. error) } \\
\hline & intercept & trend & cycle & irreg. & trend & cycle & irreg. \\
\hline NGDP & $\begin{array}{c}-3.338 \\
(3.144) \\
1.127\end{array}$ & $\begin{array}{c}1.004 \\
(0.004) \\
1.203\end{array}$ & $\begin{array}{c}-0.040^{*} \\
(0.142) \\
54.006\end{array}$ & $\begin{array}{c}-0.118^{*} \\
(0.451) \\
6.133\end{array}$ & $\begin{array}{c}1.000 \\
(0.000) \\
0.404\end{array}$ & $\begin{array}{c}-0.061^{*} \\
(0.135) \\
62.255\end{array}$ & $\begin{array}{c}-0.098^{*} \\
(0.462) \\
5.650\end{array}$ \\
\hline PGDP & $\begin{array}{c}3.543 \\
(3.752) \\
0.892\end{array}$ & $\begin{array}{c}0.995 \\
(0.006) \\
0.767\end{array}$ & $\begin{array}{c}0.742 \\
(0.162) \\
2.543\end{array}$ & $\begin{array}{c}-0.166^{*} \\
(0.497) \\
5.500\end{array}$ & $\begin{array}{c}1.000^{*} \\
(0.000) \\
6.259\end{array}$ & $\begin{array}{c}0.805 \\
(0.143) \\
1.852\end{array}$ & $\begin{array}{c}-0.201^{*} \\
(0.493) \\
5.946\end{array}$ \\
\hline UNEMP & $\begin{array}{c}9.921 \\
(9.295) \\
1.139\end{array}$ & $\begin{array}{c}0.945 \\
(0.052) \\
1.110\end{array}$ & $\begin{array}{c}0.139^{*} \\
(0.115) \\
56.251\end{array}$ & $\begin{array}{c}-0.501^{*} \\
(0.436) \\
11.855\end{array}$ & $\begin{array}{c}0.999 \\
(0.005) \\
0.018\end{array}$ & $\begin{array}{c}0.103^{*} \\
(0.108) \\
68.515\end{array}$ & $\begin{array}{c}-0.446^{*} \\
(0.436) \\
10.978\end{array}$ \\
\hline INDPROD & $\begin{array}{c}-10.240 \\
(7.682) \\
1.777\end{array}$ & $\begin{array}{c}1.019 \\
(0.013) \\
2.104\end{array}$ & $\begin{array}{c}-0.119^{*} \\
(0.098) \\
129.042\end{array}$ & $\begin{array}{c}0.089^{*} \\
(0.393) \\
5.376\end{array}$ & $\begin{array}{c}1.002^{*} \\
(0.001) \\
12.459\end{array}$ & $\begin{array}{c}-0.117^{*} \\
(0.101) \\
123.125\end{array}$ & $\begin{array}{c}0.087^{*} \\
(0.392) \\
5.435\end{array}$ \\
\hline HOUSING & $\begin{array}{c}20.545^{*} \\
(2.756) \\
55.579\end{array}$ & $\begin{array}{c}0.553^{*} \\
(0.065) \\
46.629\end{array}$ & $\begin{array}{c}0.076^{*} \\
(0.115) \\
64.149\end{array}$ & $\begin{array}{c}-0.012^{*} \\
(0.195) \\
26.838\end{array}$ & $\begin{array}{c}1.000 \\
(0.023) \\
0.000\end{array}$ & $\begin{array}{c}-0.406^{*} \\
(0.105) \\
178.401\end{array}$ & $\begin{array}{c}0.107^{*} \\
(0.308) \\
8.389\end{array}$ \\
\hline
\end{tabular}

This table shows the parameter estimates in forecast regression (13) with $h=5$, of the professional forecasts on the low-pass filter decomposition, with and without intercept. Due to missing values, the estimation sample starts at 1974Q4. For additional information, see the note following Table 6.

\section{$5 \quad$ Further Results}

In this section we perform some extra analyses to shed light on our results and provide more insight on the value of the professional forecasts. First, we assess the robustness of the fixed variance of the irregular component in the state space framework against a range of values. Next, we compare the forecasts of a basic time series model with the professional forecasts with respect to their ability to forecast the irregular component and with respect to accuracy. Finally, we examine the forecast regression in Section 4.2 with lagged trend, cycle and irregular components. 


\subsection{Sensitivity to Fixed Variance}

To estimate the components in the state space framework, the variance of the irregular component is fixed to the value of the variance of the estimated irregular component in the low-pass filter. To assess how the forecast regression results are affected by this restriction, we perform a sensitivity analysis on the value of the variance of the irregular component. Figure 3 shows the sensitivity of the estimated coefficients in the forecast regression of nominal GDP based on the estimated components in the state space model. Figure E1 up to Figure E4 in Appendix E show the sensitivities for the other time series.

The figure shows the values of the estimated coefficients with error bands of one standard error, for different values of the standard deviation of the estimated irregular component. The asterisks show the estimated coefficients at the value of the standard deviation of the estimated irregular component in the low-pass filter. The coefficients of the intercept, trend, and business-cycle show hardly any differences over the interval. The coefficient of the irregular component seems to deviate more from the weight expected in a perfect forecast when the standard deviation of the estimated irregular component decreases. So the choice to fix the variance of the irregular component is not likely to influence the results found in the forecast regressions.

\subsection{Model-based Forecast Decomposition}

Based on the forecast regressions we find that the mean of the Survey of Professional Forecasters only explains little of the time series variation due to the irregular component. This is surprising when we presume that professional forecasters may adapt faster and be more flexible than pure model-based prediction methods. However, we do not expect an econometric model to capture the irregular component. To investigate this conjecture, we regress model forecasts on the estimated components of the historical time series.

We generate forecasts with an autoregressive model of order $p, A R(p)$, for the first difference of the log series estimated on a moving window of ten years of quarterly observations. The order $p$ is selected for each forecasting period by means of the Schwartz information criterion on the moving window. The model is estimated using the latest vintage of real-time historical data available at the 
Table 11: $A R(p)$ Model Forecast Regressions $(h=1)$ for Nominal GDP

\begin{tabular}{|c|c|c|c|c|c|c|c|}
\hline & \multicolumn{4}{|c|}{ Estimate (Std. error) } & \multicolumn{3}{|c|}{ Estimate (Std. error) } \\
\hline & intercept & trend & cycle & irreg. & trend & cycle & irreg. \\
\hline NGDP & $\begin{array}{c}-2.154^{*} \\
(0.783) \\
7.572\end{array}$ & $\begin{array}{c}1.002^{*} \\
(0.001) \\
7.565\end{array}$ & $\begin{array}{c}0.971 \\
(0.051) \\
0.321\end{array}$ & $\begin{array}{c}0.010^{*} \\
(0.163) \\
36.643\end{array}$ & $\begin{array}{c}1.000 \\
(0.000) \\
0.497\end{array}$ & $\begin{array}{c}0.980 \\
(0.054) \\
0.138\end{array}$ & $\begin{array}{c}0.009^{*} \\
(0.172) \\
33.031\end{array}$ \\
\hline PGDP & $\begin{array}{c}-1.222 \\
(0.778) \\
2.466\end{array}$ & $\begin{array}{c}1.002 \\
(0.001) \\
2.449\end{array}$ & $\begin{array}{c}0.983 \\
(0.061) \\
0.078\end{array}$ & $\begin{array}{c}-0.117^{*} \\
(0.315) \\
12.618\end{array}$ & $\begin{array}{c}1.000 \\
(0.000) \\
0.054\end{array}$ & $\begin{array}{c}0.996 \\
(0.060) \\
0.003\end{array}$ & $\begin{array}{c}-0.122^{*} \\
(0.321) \\
12.172\end{array}$ \\
\hline UNEMP & $\begin{array}{c}2.439 \\
(4.348) \\
0.315\end{array}$ & $\begin{array}{c}0.986 \\
(0.024) \\
0.351\end{array}$ & $\begin{array}{c}1.029 \\
(0.047) \\
0.386\end{array}$ & $\begin{array}{c}-0.026^{*} \\
(0.351) \\
8.520\end{array}$ & $\begin{array}{c}0.999 \\
(0.002) \\
0.178\end{array}$ & $\begin{array}{c}1.023 \\
(0.046) \\
0.244\end{array}$ & $\begin{array}{c}-0.015^{*} \\
(0.349) \\
8.462\end{array}$ \\
\hline INDPROD & $\begin{array}{c}-1.322 \\
(3.039) \\
0.189\end{array}$ & $\begin{array}{c}1.002 \\
(0.006) \\
0.187\end{array}$ & $\begin{array}{c}1.055 \\
(0.054) \\
1.042\end{array}$ & $\begin{array}{c}0.309^{*} \\
(0.251) \\
7.582\end{array}$ & $\begin{array}{c}1.000 \\
(0.000) \\
0.036\end{array}$ & $\begin{array}{c}1.055 \\
(0.054) \\
1.045\end{array}$ & $\begin{array}{c}0.309^{*} \\
(0.250) \\
7.638\end{array}$ \\
\hline HOUSING & $\begin{array}{c}1.834 \\
(1.370) \\
1.792\end{array}$ & $\begin{array}{c}0.962 \\
(0.031) \\
1.455\end{array}$ & $\begin{array}{c}1.032 \\
(0.062) \\
0.260\end{array}$ & $\begin{array}{c}0.024^{*} \\
(0.170) \\
33.081\end{array}$ & $\begin{array}{c}1.003 \\
(0.017) \\
0.029\end{array}$ & $\begin{array}{c}0.991 \\
(0.060) \\
0.022\end{array}$ & $\begin{array}{c}0.034^{*} \\
(0.173) \\
31.051\end{array}$ \\
\hline
\end{tabular}

This table shows the parameter estimates in forecast regression (13) of the $A R(p)$ model forecasts on the low-pass filter decomposition, with and without intercept. White standard errors are reported in parentheses together with Wald test statistics on the null hypothesis that the coefficient is equal to the weight expected in a perfect forecast. An asterisk $(*)$ denotes that the coefficient significantly differs from the weight expected in a perfect forecast at the five percent significance level.

moment of forecasting using a similar approach as in the previous section.

Table 11 shows the forecast regression results of the one-step-ahead predictions in the sample from the last quarter of 1971 to the first quarter of 2013. The overall picture resembles the results in Section 4.2. Both the estimated weights of the components estimated in the spectral analysis as the estimated weights of the components estimated in the state space model show that the model-based predictions can only explain the trend and cycle components. The forecasts do not contain any information about the irregular component and the weight is negative in case one opts for a state space model approach to decompose the time series. 


\subsection{Forecast Accuracy}

Our previous results show that the professional forecasters predict little of the irregular component. To investigate the value-added of professional forecasts, we compare them to simple model-based predictions. We obtain these predictions from the Kalman filter in the state space model (6)-(10) in which we do not fix a signal-to-noise ratio. So the irregular component estimated by the state space model is allowed to go to zero.

We generate the one-step-ahead predictions in the sample from 1980Q4 up to 2014Q2 using an expanding window consisting of the the latest vintage of realtime historical data available at the moment of forecasting. The first estimation sample starts at 1947Q1. The data is provided in the Real-Time Data Set for Macroeconomists of the Federal Reserve Bank of Philadelphia. We account for changing base years in the GDP price index and the industrial production index by scaling all data in the Real-Time Data Set and the Survey of Professional Forecasters by the value for 1980Q4 in the latest vintage available at the moment of forecasting.

Table 12 shows the mean squared prediction errors for the forecasts of the state space model and the Survey of Professional Forecasters. Except for PGDP, the state space model is significantly outperformed on a five percent significance level by the professional forecasters based on all predictions. Although the professional forecasters cannot capture all variation in the irregular component, they probably do a better job in forecasting the trend and the business-cycle than the state space model over the whole time period. When we only consider the predictions for the last 20 quarters, the state space model is only significantly outperformed for unemployment but again the professional forecasters are more accurate in terms of MSPE.

Figure 4 shows the nominal GDP forecasts, ${ }^{4}$ the confidence intervals and the actual historical time series for the evaluation period including the last five years of the sample. The confidence interval for the Survey of Professional Forecasters

\footnotetext{
${ }^{4}$ Due to a change in the Bureau of Economic Analysis (BEA) definition of GDP, Figure 4 shows a jump in 2013. However, our results are robust to these kind of changes, as the analysis on the first differences of the series in Table 6 shows. We thank an anonymous referee for pointing this out.
} 
Table 12: Mean Squared Prediction Errors

\begin{tabular}{|c|c|c|c|c|c|c|}
\hline & \multicolumn{3}{|c|}{ Last 40 quarters } & \multicolumn{3}{|c|}{ Last 20 quarters } \\
\hline & $\mathrm{SPF}$ & SSM & DM & $\mathrm{SPF}$ & SSM & $\mathrm{DM}$ \\
\hline NGDP & 0.749 & 0.884 & $-3.618^{*}$ & 0.830 & 0.844 & -0.194 \\
\hline PGDP & 0.554 & 0.562 & -0.731 & 0.573 & 0.584 & -0.503 \\
\hline UNEMP & 2.299 & 4.462 & $-5.739 *$ & 1.972 & 4.508 & $-2.387^{*}$ \\
\hline INDPROD & 1.136 & 1.453 & $-2.521^{*}$ & 0.816 & 1.171 & -1.216 \\
\hline HOUSING & 6.516 & 8.673 & $-3.706^{*}$ & 7.083 & 9.082 & -1.246 \\
\hline
\end{tabular}

This table shows the mean squared prediction error of the one-step ahead predictions of the Survey of Professional Forecasters (SPF) and the state space model (SSM), together with the Diebold and Mariano (1995) test statistic. We have real-time data from 1947Q1 to 2014Q1 from which we use an expanding window in the state space model to predict the last 40 quarters. Mean squared prediction errors are reported over all predictions and the predictions for the last 20 quarters.

is constructed by the lowest and highest individual forecast and the state space prediction comes along with a covariance matrix from which we retrieve two times the standard deviation. The two predictions are very close to each other and follow an almost identical pattern. Where the constructed confidence interval of the professional forecasts seems narrower over the whole evaluation period, it has some outliers, while the confidence interval of the state space predictions is quite stable. Overall, the structural time series model produces almost the same predictions as the Survey of Professional Forecasters.

\subsection{Forecast Regression with Lagged Components}

To shed light on the information in the professional forecasts, we now also consider the time series decomposition of the mean of the Professional Forecasters. Figure 5 and Figure 6 show these decompositions together with the decomposition of the historical time series based on a spectral analysis and a state space model, respectively. In both figures, the business-cycle and the irregular component estimated from the forecasts seem to lag behind these components estimated from the historical time series. 
Table 13: Forecast Regressions $(h=1)$ on Lagged Estimated Components

\begin{tabular}{|c|c|c|c|c|c|c|c|}
\hline & \multicolumn{4}{|c|}{ Estimate (Std. error) } & \multicolumn{3}{|c|}{ Estimate (Std. error) } \\
\hline & intercept & trend & cycle & irreg. & trend & cycle & irreg. \\
\hline NGDP & $\begin{array}{c}6.610^{*} \\
(0.495) \\
178.283\end{array}$ & $\begin{array}{c}0.994^{*} \\
(0.001) \\
110.964\end{array}$ & $\begin{array}{c}0.989 \\
(0.025) \\
0.207\end{array}$ & $\begin{array}{c}0.951 \\
(0.094) \\
0.272\end{array}$ & $\begin{array}{c}1.002^{*} \\
(0.000) \\
610.593\end{array}$ & $\begin{array}{c}0.958 \\
(0.041) \\
1.081\end{array}$ & $\begin{array}{c}0.953 \\
(0.155) \\
0.092\end{array}$ \\
\hline PGDP & $\begin{array}{c}-9.641^{*} \\
(1.029) \\
87.871\end{array}$ & $\begin{array}{c}1.022^{*} \\
(0.002) \\
100.860\end{array}$ & $\begin{array}{c}0.998 \\
(0.006) \\
0.136\end{array}$ & $\begin{array}{c}1.002 \\
(0.010) \\
0.054\end{array}$ & $\begin{array}{c}1.002^{*} \\
(0.000) \\
487.419\end{array}$ & $\begin{array}{c}1.008 \\
(0.004) \\
3.751\end{array}$ & $\begin{array}{c}0.999 \\
(0.007) \\
0.020\end{array}$ \\
\hline UNEMP & $\begin{array}{c}-3.270 \\
(3.554) \\
0.847\end{array}$ & $\begin{array}{c}1.024 \\
(0.020) \\
1.459\end{array}$ & $\begin{array}{c}0.896^{*} \\
(0.031) \\
11.560\end{array}$ & $\begin{array}{c}0.541 \\
(0.247) \\
3.462\end{array}$ & $\begin{array}{c}1.006^{*} \\
(0.002) \\
12.175\end{array}$ & $\begin{array}{c}0.905^{*} \\
(0.029) \\
10.747\end{array}$ & $\begin{array}{c}0.528 \\
(0.247) \\
3.657\end{array}$ \\
\hline INDPROD & $\begin{array}{c}0.245 \\
(4.915) \\
0.002\end{array}$ & $\begin{array}{c}1.001 \\
(0.010) \\
0.004\end{array}$ & $\begin{array}{c}0.974^{*} \\
(0.013) \\
4.268\end{array}$ & $\begin{array}{c}0.943 \\
(0.031) \\
3.425\end{array}$ & $\begin{array}{c}1.001^{*} \\
(0.000) \\
38.798\end{array}$ & $\begin{array}{c}0.974^{*} \\
(0.013) \\
4.319\end{array}$ & $\begin{array}{c}0.943 \\
(0.031) \\
3.385\end{array}$ \\
\hline HOUSING & $\begin{array}{c}-0.123 \\
(0.863) \\
0.020\end{array}$ & $\begin{array}{c}0.971 \\
(0.021) \\
1.986\end{array}$ & $\begin{array}{c}0.866^{*} \\
(0.033) \\
16.395\end{array}$ & $\begin{array}{c}0.558^{*} \\
(0.077) \\
32.577\end{array}$ & $\begin{array}{c}0.968^{*} \\
(0.009) \\
13.202\end{array}$ & $\begin{array}{c}0.868^{*} \\
(0.032) \\
16.674\end{array}$ & $\begin{array}{c}0.557^{*} \\
(0.077) \\
33.377\end{array}$ \\
\hline
\end{tabular}

This table shows the parameter estimates in forecast regression (13) of the professional forecasts on the lagged values of the low-pass filter decomposition, with and without intercept. White standard errors are reported in parentheses together with Wald test statistics on the null hypothesis that the coefficient is equal to the weight expected in a perfect forecast. An asterisk $(*)$ denotes that the coefficient significantly differs from the weight expected in a perfect forecast at the five percent significance level.

Since the decompositions of the mean of the forecasts of the Survey of Professional forecasters suggest that the forecasts are biased towards lagged values of nominal GDP, we regress the professional forecasts on the lagged values of the components estimated from the historical time series. Table 13 shows the results for all series. Due to small standard errors the weights of the lagged estimated trend and cycle sometimes differ significantly from one, but the weights of the irregular component do not significantly differ from one, except for housing starts. This suggests that the professional forecasters explain the value of the series the current period, which is already published, instead of explaining irregular events in the future. 


\section{Conclusion}

In this paper we have examined what professional forecasters actually explain. We use a spectral analysis and a state space model to decompose economic time series into three components; a trend, a business-cycle, and an irregular component. Thereafter we examine which components are explained by the Survey of Professional Forecasters in a regression of the mean forecasts on the estimated components of the actual historical time series. We run these regressions based on the components estimated by the low-pass filters in the spectral analysis and the components estimated in a state space model. Both approaches lead to approximately the same results. For most time series we cannot reject that the mean of the professional forecasts can predict the variation in the trend and the businesscycle, but there is little or no predictive power for the variation in the irregular component. A simple state space model, which is commonly used to estimate trends and cycles in time series, can produce almost the same predictions.

The results suggest that both econometric models and the mean of the professional forecasts contain little information about the variation in the irregular component. This result is not surprising when professional forecasters also use model-based techniques to construct their predictions and the irregular component is characterized by weak persistence. On the other hand, irregular events may be of little interest to policy makers. When the latter is the case, both econometric models and professional forecasters perform well in capturing the trend and the business-cycle. The fact that in some cases the professional forecasters capture a small amount of the variation in the irregular components, may explain why some businesses and policymakers rely on professional forecasters.

Since the time series in the database of the Survey of Professional Forecasters are already seasonally adjusted, the time series decompositions are limited to a trend, cycle and irregular component. An interesting topic for future research is to analyze whether professional forecasters are able to predict seasonal variation by extending our analysis with a seasonal component and seasonally unadjusted data. 


\section{References}

Altug, S. and Çakmaklı, C. Forecasting inflation using survey expectations and target inflation: Evidence for brazil and turkey. International Journal of Forecasting, 32(1):138-153, 2016.

Ang, A., Bekaert, G., and Wei, M. Do macro variables, asset markets, or surveys forecast inflation better? Journal of Monetary Economics, 54(4):1163-1212, 2007.

Baxter, M. Real exchange rates and real interest differentials: Have we missed the business-cycle relationship? Journal of Monetary Economics, 33(1):5-37, 1994.

Baxter, M. and King, R. G. Measuring business cycles: Approximate band-pass filters for economic time series. Review of Economics and Statistics, 81(4):575593, 1999.

Billio, M., Casarin, R., Ravazzolo, F., and Van Dijk, H. K. Time-varying combinations of predictive densities using nonlinear filtering. Journal of Econometrics, 177(2):213-232, 2013.

Christiano, L. J. and Fitzgerald, T. J. The band pass filter. International Economic Review, 44(2):435-465, 2003.

Clements, M. P. Are professional macroeconomic forecasters able to do better than forecasting trends? Journal of Money, Credit and Banking, 47(2-3):349$382,2015$.

Colander, D., Goldberg, M., Haas, A., Juselius, K., Kirman, A., Lux, T., and Sloth, B. The financial crisis and the systemic failure of the economics profession. Critical Review, 21(2-3):249-267, 2009.

Croushore, D. and Stark, T. A real-time data set for macroeconomists. Journal of econometrics, 105(1):111-130, 2001.

Diebold, F. X. and Mariano, R. S. Comparing predictive accuracy. Journal of Business \& Economic Statistics, 13(3):253-263, 1995. 
Dungey, M., Jacobs, J. P., Tian, J., and Van Norden, S. Trend in cycle or cycle in trend? new structural identifications for unobserved-components models of us real gdp. Macroeconomic Dynamics, 19(4):776-790, 2015.

Durbin, J. and Koopman, S. J. Time series analysis by state space methods. Number 38. Oxford University Press, 2012.

Engle, R. F. and Granger, C. Co-integration and error correction: Representation, estimation, and testing. Econometrica, 55(2):251-276, 1987.

Franses, P. H. and Legerstee, R. Do experts' adjustments on model-based sku-level forecasts improve forecast quality? Journal of Forecasting, 29(3):331-340, 2010.

Franses, P. H., Kranendonk, H. C., and Lanser, D. One model and various experts: Evaluating dutch macroeconomic forecasts. International Journal of Forecasting, 27(2):482-495, 2011.

Ghysels, E. and Wright, J. H. Forecasting professional forecasters. Journal of Business \& Economic Statistics, 27(4):504-516, 2009.

Gil-Alana, L., Moreno, A., and Pérez de Gracia, F. Exploring survey-based inflation forecasts. Journal of Forecasting, 31(6):524-539, 2012.

Harvey, A. C. Trends and cycles in macroeconomic time series. Journal of Business Ef Economic Statistics, 3(3):216-227, 1985.

Harvey, A. C. Forecasting, structural time series models and the Kalman filter. Cambridge University Press, 1990.

Harvey, A. C. and Trimbur, T. M. General model-based filters for extracting cycles and trends in economic time series. Review of Economics and Statistics, 85(2): 244-255, 2003.

Hyndman, R. J. and Koehler, A. B. Another look at measures of forecast accuracy. International Journal of Forecasting, 22(4):679-688, 2006.

Isiklar, G., Lahiri, K., and Loungani, P. How quickly do forecasters incorporate news? evidence from cross-country surveys. Journal of Applied Econometrics, 21(6):703-725, 2006. 
Kozicki, S. and Tinsley, P. A. Effective use of survey information in estimating the evolution of expected inflation. Journal of Money, Credit and Banking, 44 (1):145-169, 2012.

Leitch, G. and Ernesttanner, J. Professional economic forecasts: Are they worth their costs? Journal of Forecasting, 14(2):143-157, 1995.

MacKinnon, J. G. Numerical distribution functions for unit root and cointegration tests. Journal of Applied Econometrics, 11(6):601-618, 1996.

Mehra, Y. P. Survey measures of expected inflation: Revisiting the issues of predictive content and rationality. Economic Quarterly-Federal Reserve Bank of Richmond, 88(3):17-36, 2002.

Mertens, E. Measuring the level and uncertainty of trend inflation. Review of Economics and Statistics, (0), 2015.

Murphy, K. M. and Topel, R. H. Estimation and inference in two-step econometric models. Journal of Business \&f Economic Statistics, 20(1):88-97, 2002.

Park, J. Y. and Phillips, P. C. Statistical inference in regressions with integrated processes: Part 2. Econometric Theory, 5(01):95-131, 1989.

Pollock, D. Trend estimation and de-trending via rational square-wave filters. Journal of Econometrics, 99(2):317-334, 2000.

Stock, J. H. and Watson, M. W. Median unbiased estimation of coefficient variance in a time-varying parameter model. Journal of the American Statistical Association, 93(441):349-358, 1998.

Thomas, L. B. et al. Survey measures of expected United States inflation. Journal of Economic Perspectives, 13(4):125-144, 1999.

White, H. A heteroskedasticity-consistent covariance matrix estimator and a direct test for heteroskedasticity. Econometrica, 48(4):817-838, 1980. 
Figure 1: Historical Time Series and the Survey of Professional Forecasters
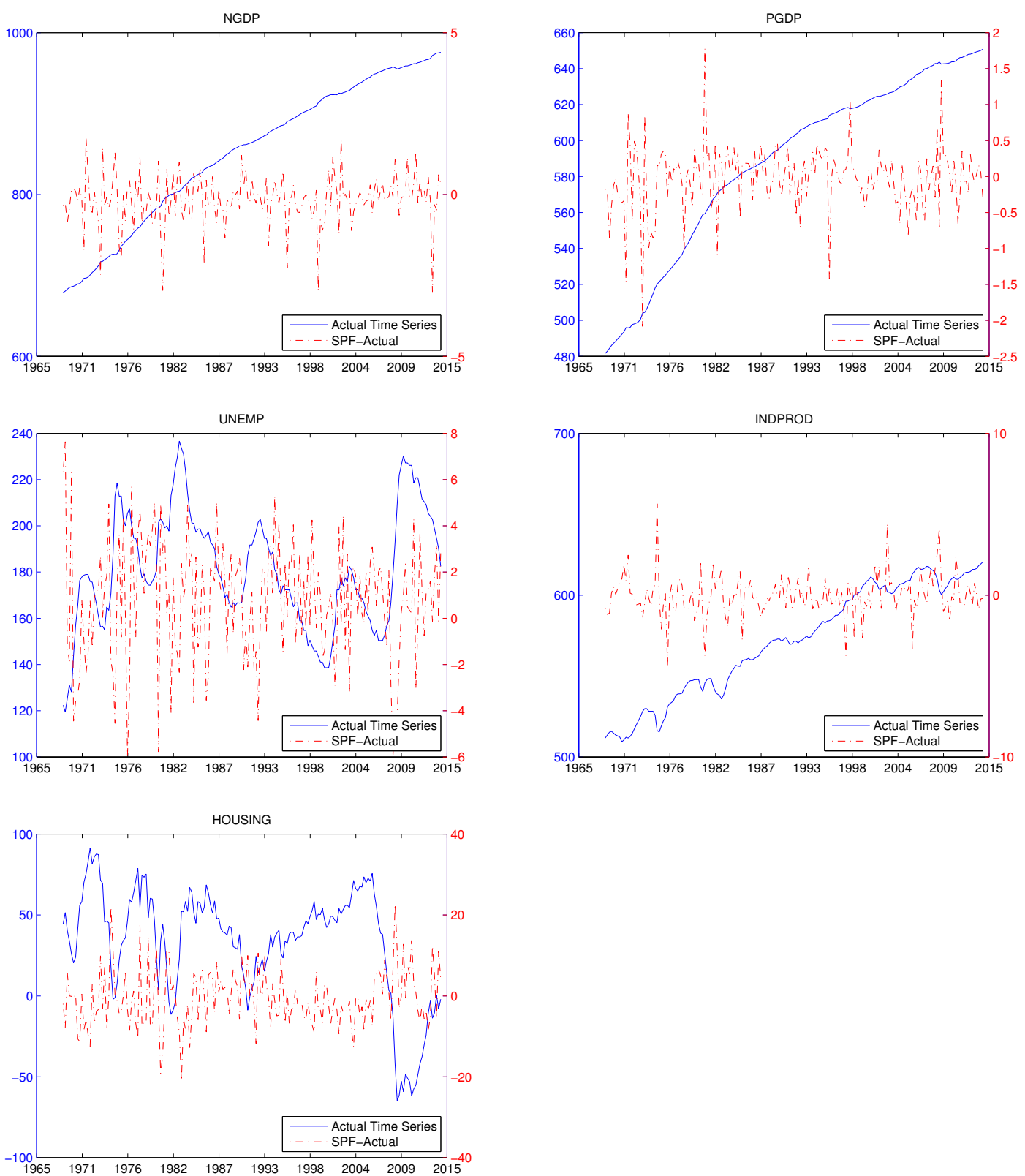

Historical time series (blue solid line, left axis) graphs together with the differences between the predictions of the Survey of Professional Forecasters and the actual values (red dashed dotted line, right axis). The figure shows the nominal GDP, GDP price index, unemployment, industrial production index, and housing starts, respectively. The time series are log transformed and multiplied by one hundred. 
Figure 2: Decomposition of Nominal GDP
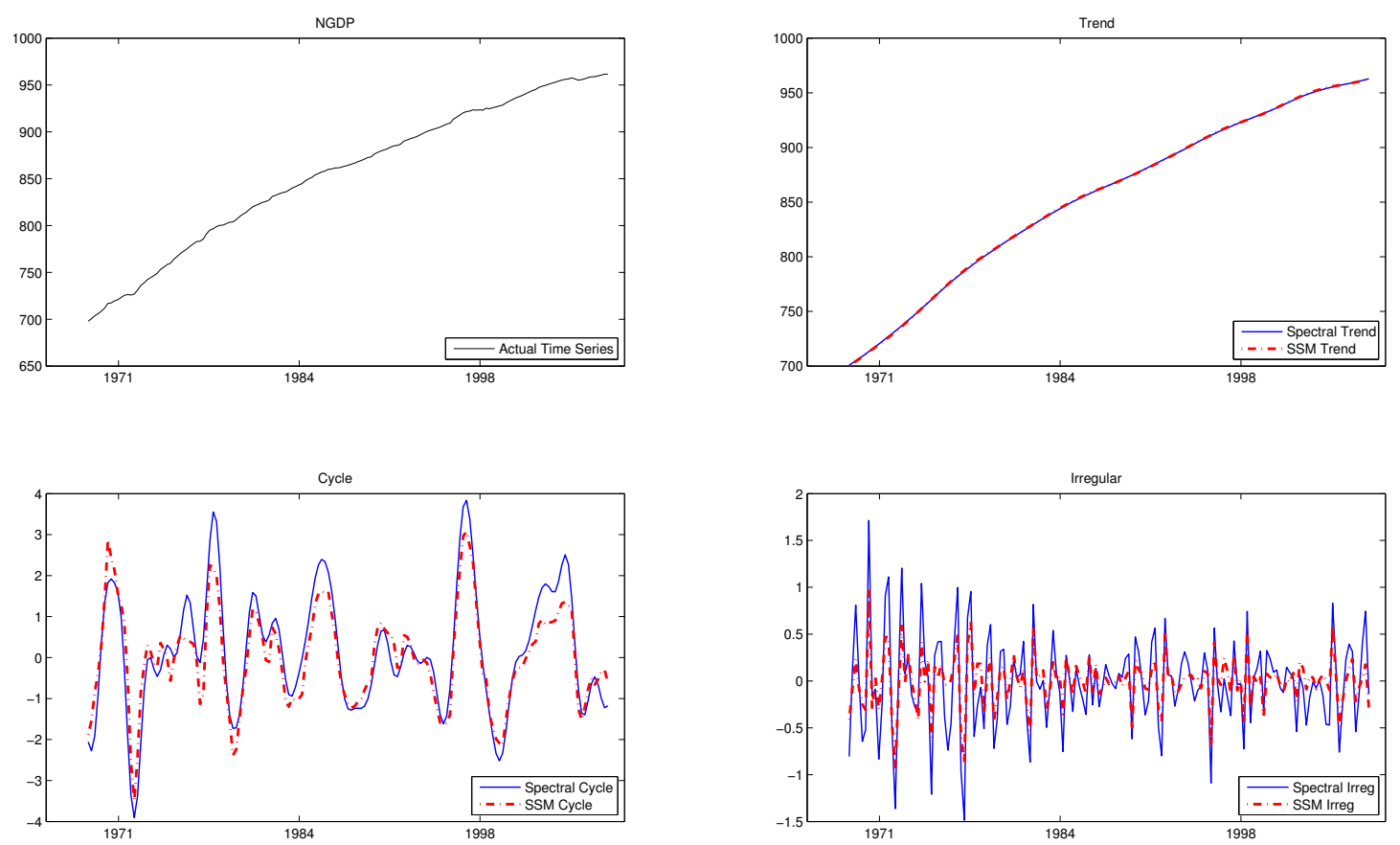

Nominal GDP decomposed in a trend, a cycle, and an irregular component by the low-pass filters and the state space model. The first window shows one hundred times the logarithm of the actual values in the historical time series and the other windows show the components estimated in the low-pass filters by a blue solid line and the components estimated in the state space model by a red dashed dotted line. 
Figure 3: Sensitivity Analysis Fixed Variance Irregular Component
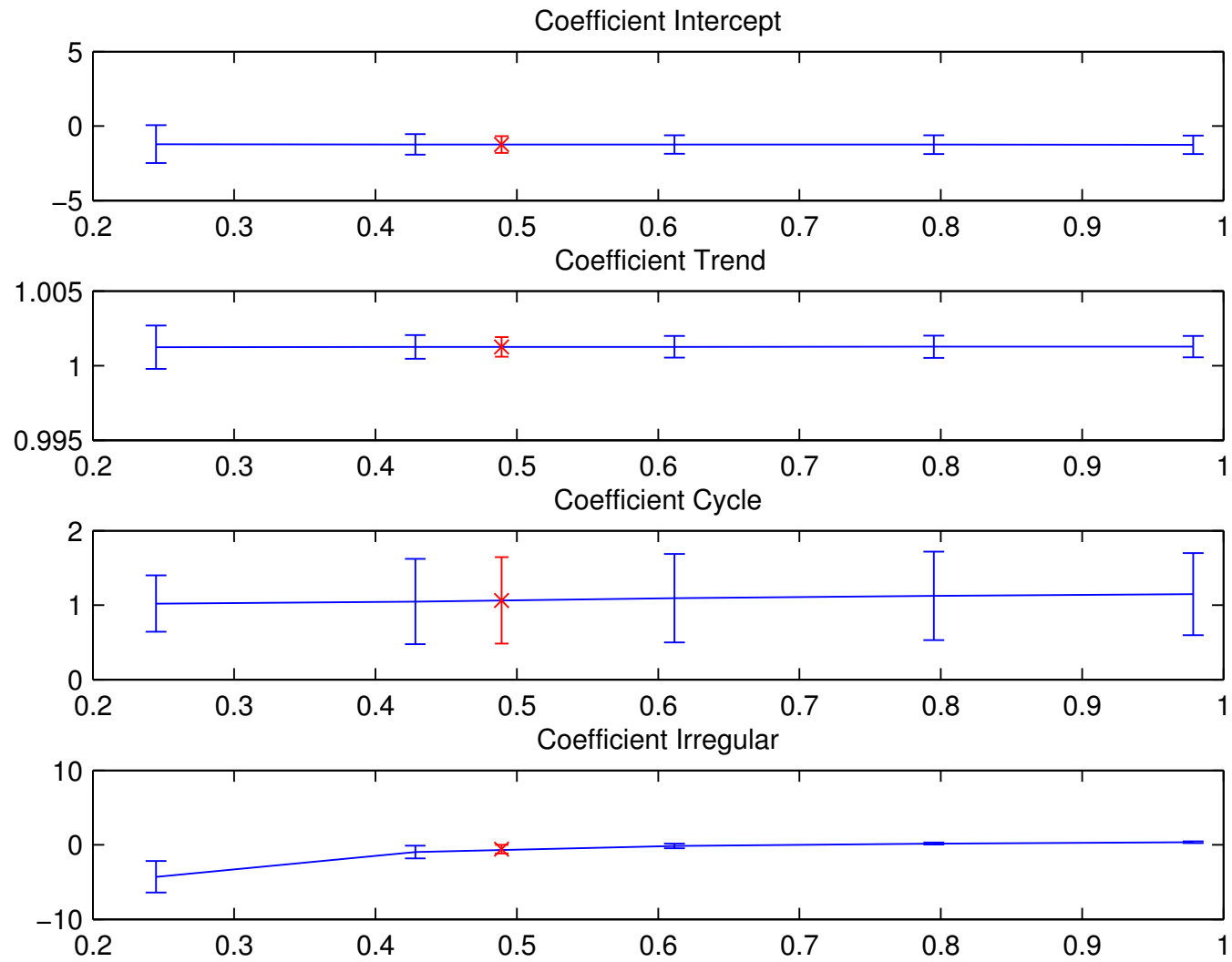

Sensitivity of the estimated coefficients in the forecast regression of nominal GDP to the standard deviation of the estimated irregular component in the state space framework. The (blue) lines show the value of the estimated coefficients with error bands of one standard error, for different values of the standard deviation of the estimated irregular component. The error bands are constructed with two-step standard errors. The (red) asterisks show the estimated coefficients at the value of the standard deviation of the estimated irregular component in the low-pass filter. 
Figure 4: Model-Based and Professional Forecasts NGDP

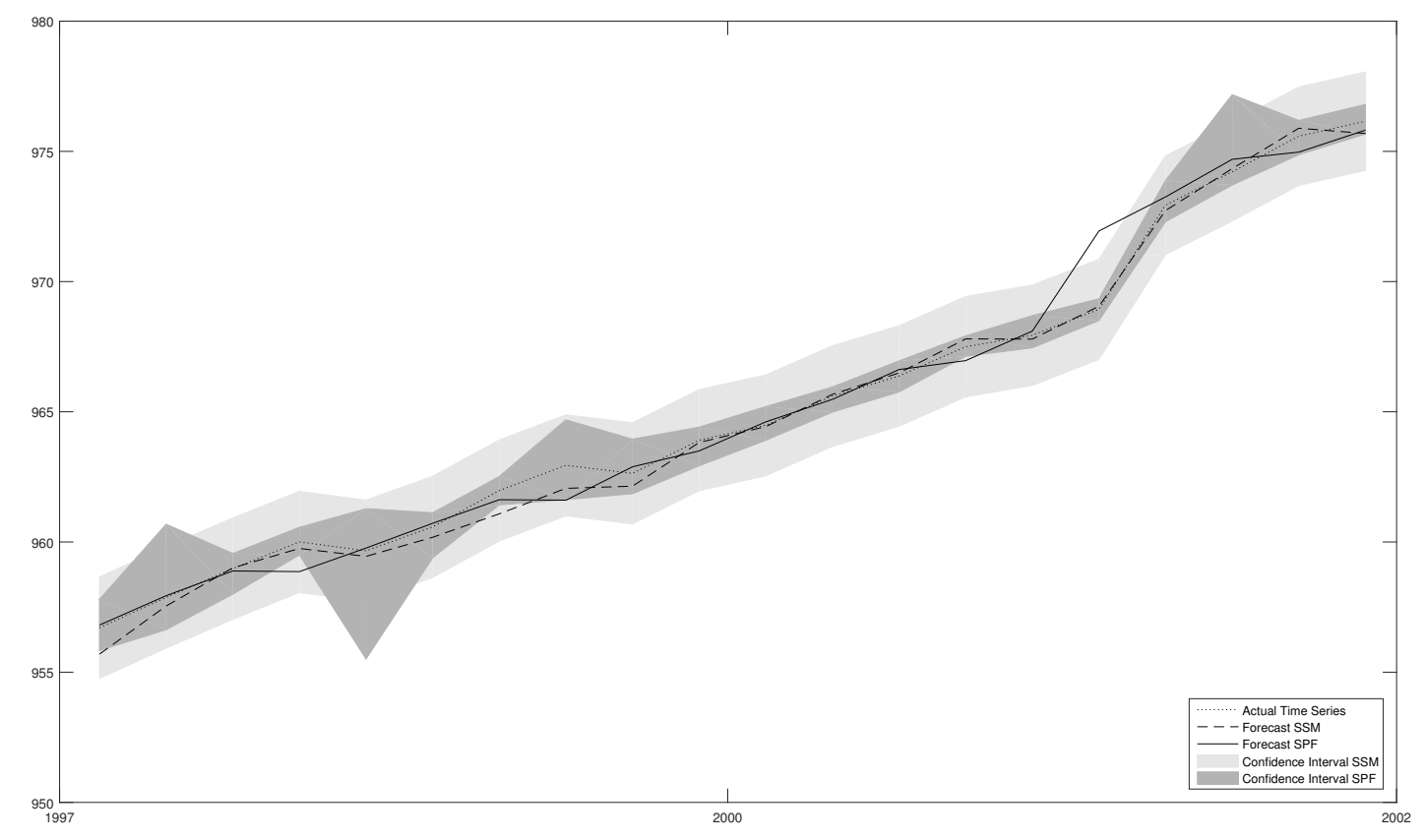

Nominal GDP predictions of the state space model (dashed line) and the Survey of Professional Forecasters (dashed dotted line) together with the actual time series (solid line). The corresponding gray surfaces represent the constructed confidence intervals of the predictions. The jump in 2013 can be explained by a change in the Bureau of Economic Analysis (BEA) definition of GDP. 
Figure 5: Decomposition of Nominal GDP in Spectral Analysis
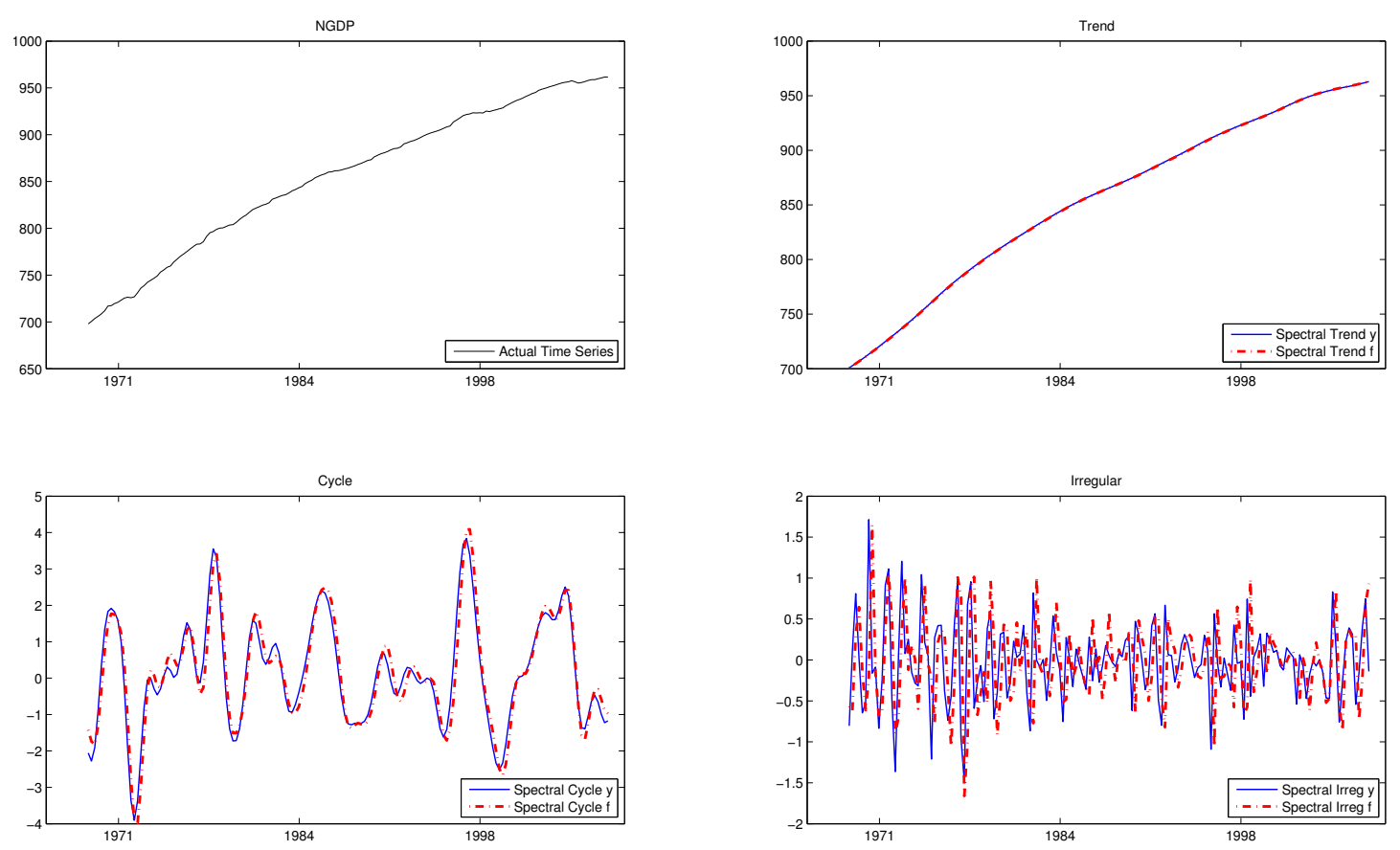

The historical time series and the mean of the forecasts of the Survey of Professional Forecasters for Nominal GDP decomposed in a trend, a cycle, and an irregular component by the lowpass filters. The first window shows one hundred times the logarithm of the actual values in the historical time series and the other windows show the estimated components of the actual historical time series by a blue solid line and the estimated components of the mean of the forecasts of the Survey of Professional Forecasters by a red dashed dotted line. 
Figure 6: Decomposition of Nominal GDP in State Space Model
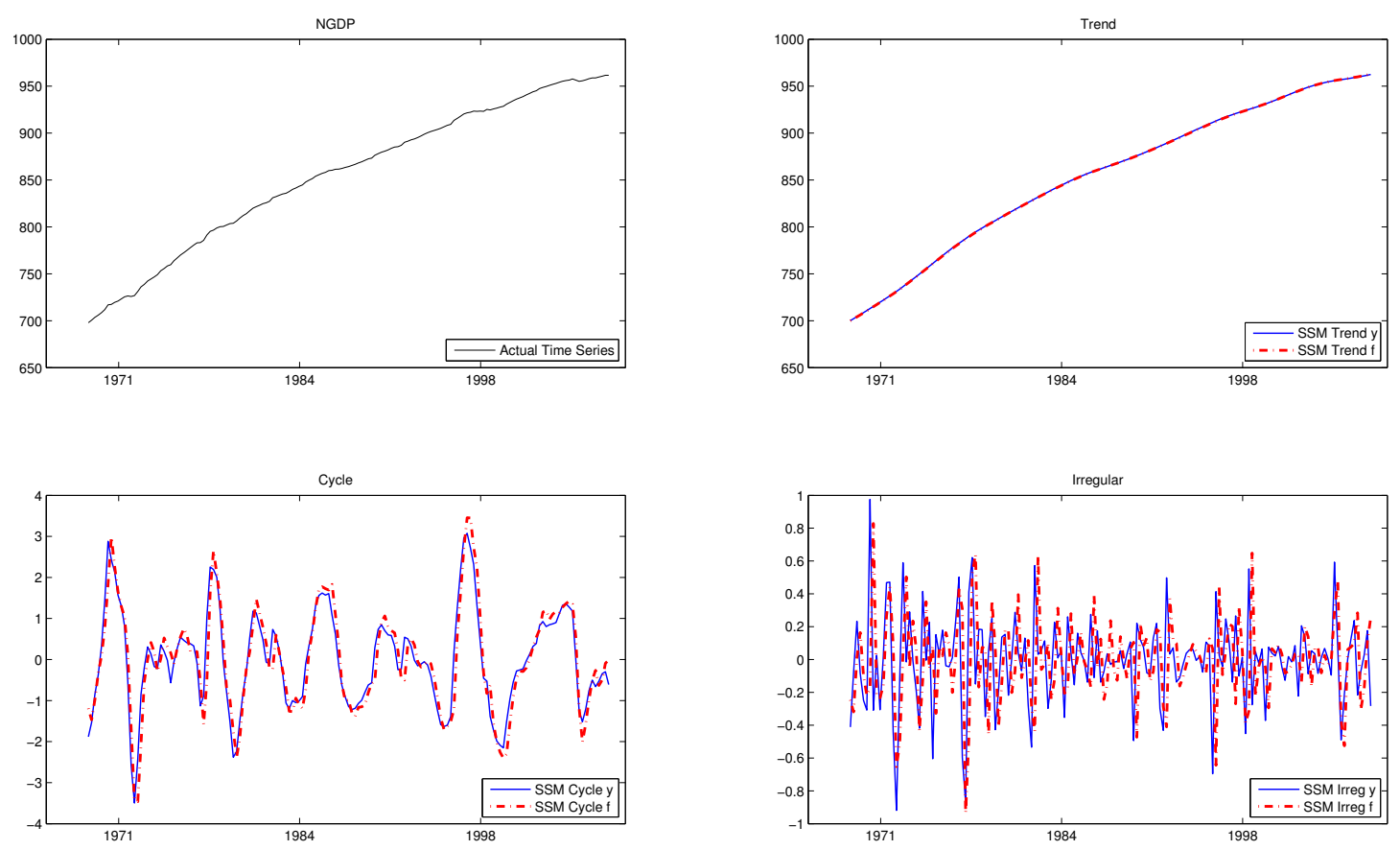

The historical time series and the mean of the forecasts of the Survey of Professional Forecasters for Nominal GDP decomposed in a trend, a cycle, and an irregular component by the state space model. The first window shows one hundred times the logarithm of the actual values in the historical time series and the other windows show the estimated components of the actual historical time series by a blue solid line and the estimated components of the mean of the forecasts of the Survey of Professional Forecasters by a red dashed dotted line. 


\section{Appendix A Time Series Decompositions}

In Subsection 4.1 we show nominal GDP decomposed in a trend, a cycle, and an irregular component by the low-pass filters and the state space model. Here we show the decompositions of the other variables; GDP price index (PGDP), unemployment (UNEMP), industrial production index (INDPROD), and housing starts (HOUSING). Each figure corresponding to a variable consist of four windows. The first window shows the actual values in the historical time series and the other windows show the components estimated in the low-pass filters by a blue solid line and the components estimated in the state space model by a red dashed dotted line. All variables are log transformed and multiplied by hundred.
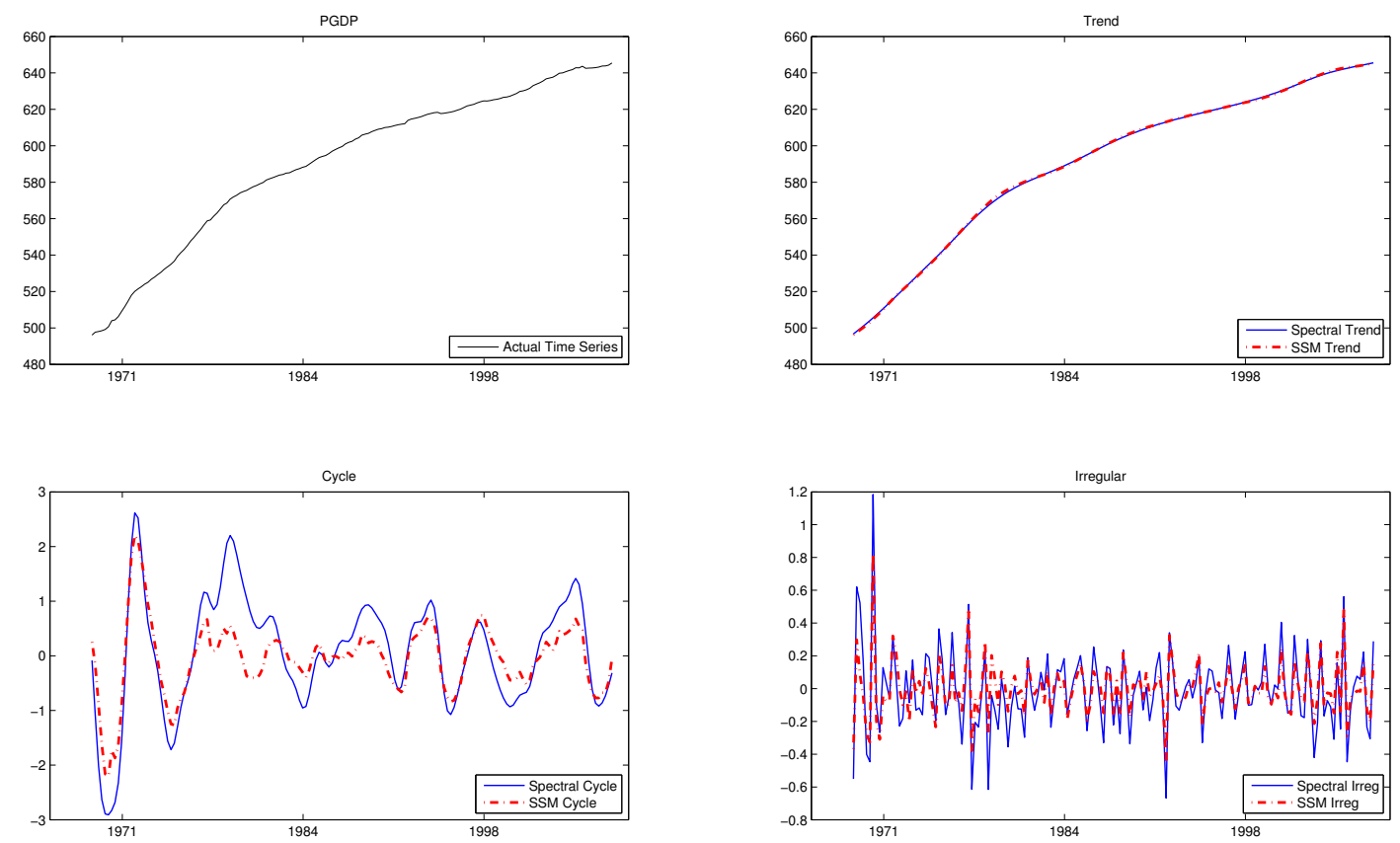

Figure A1: GDP Price Index 

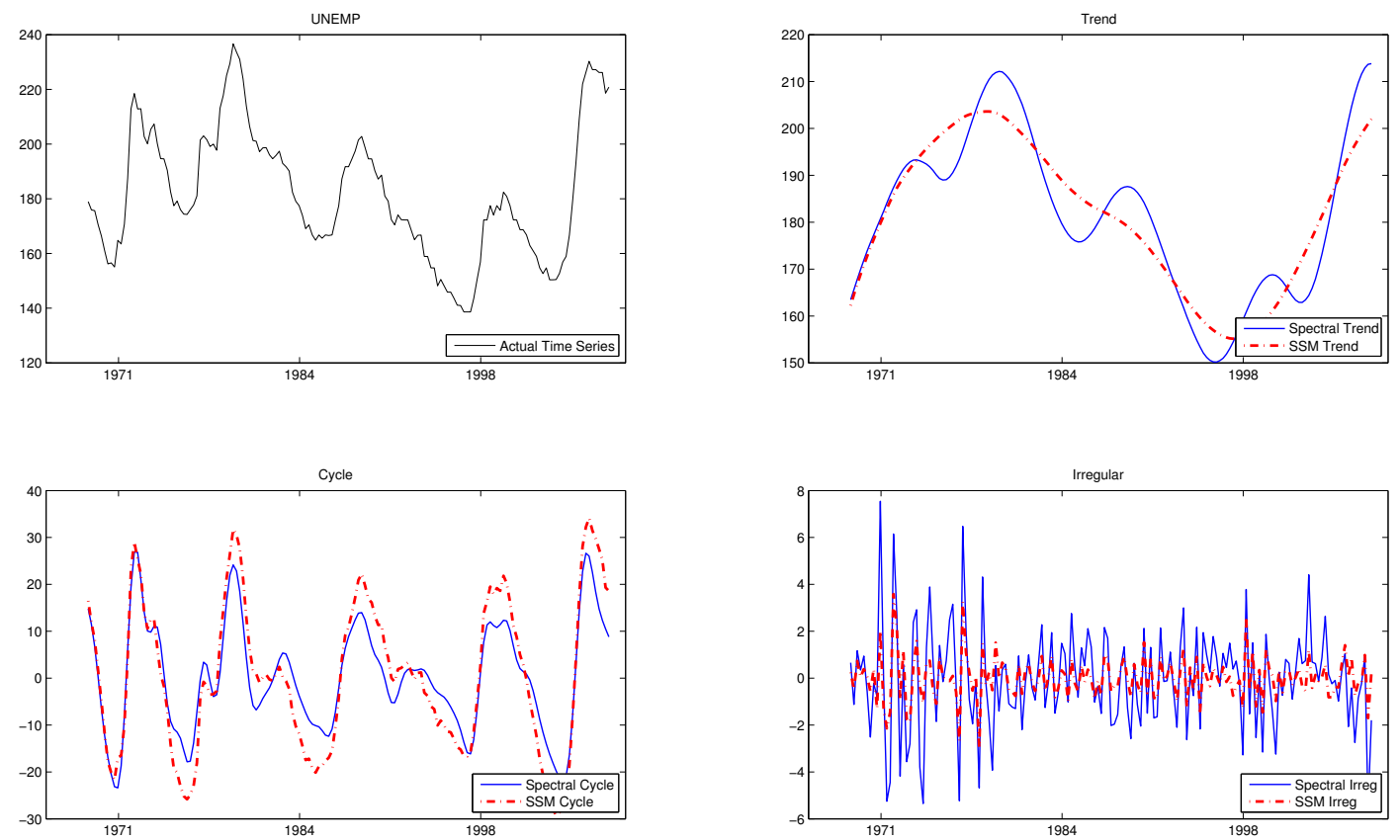

Figure A2: Unemployment
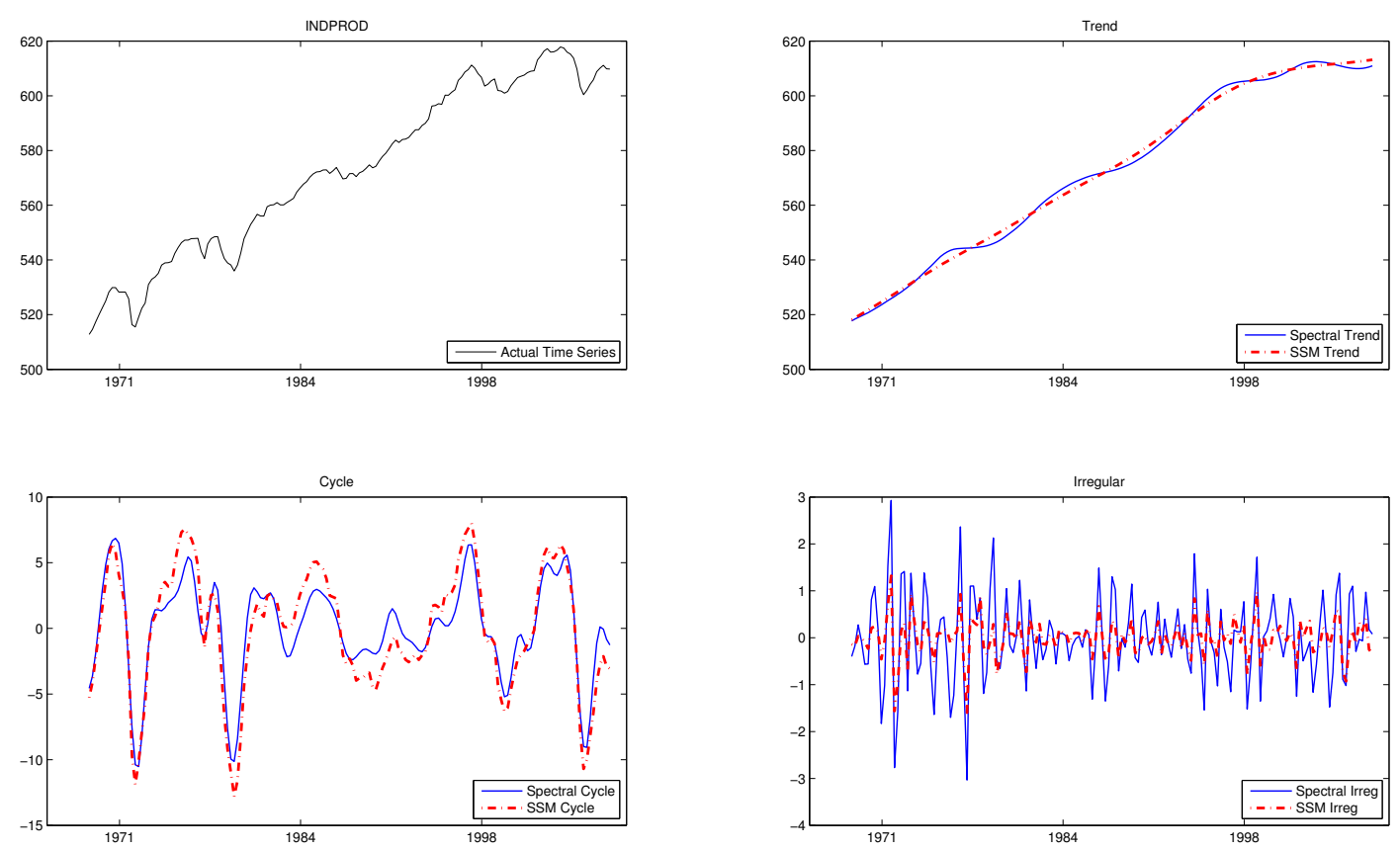

Figure A3: Industrial Production Index 

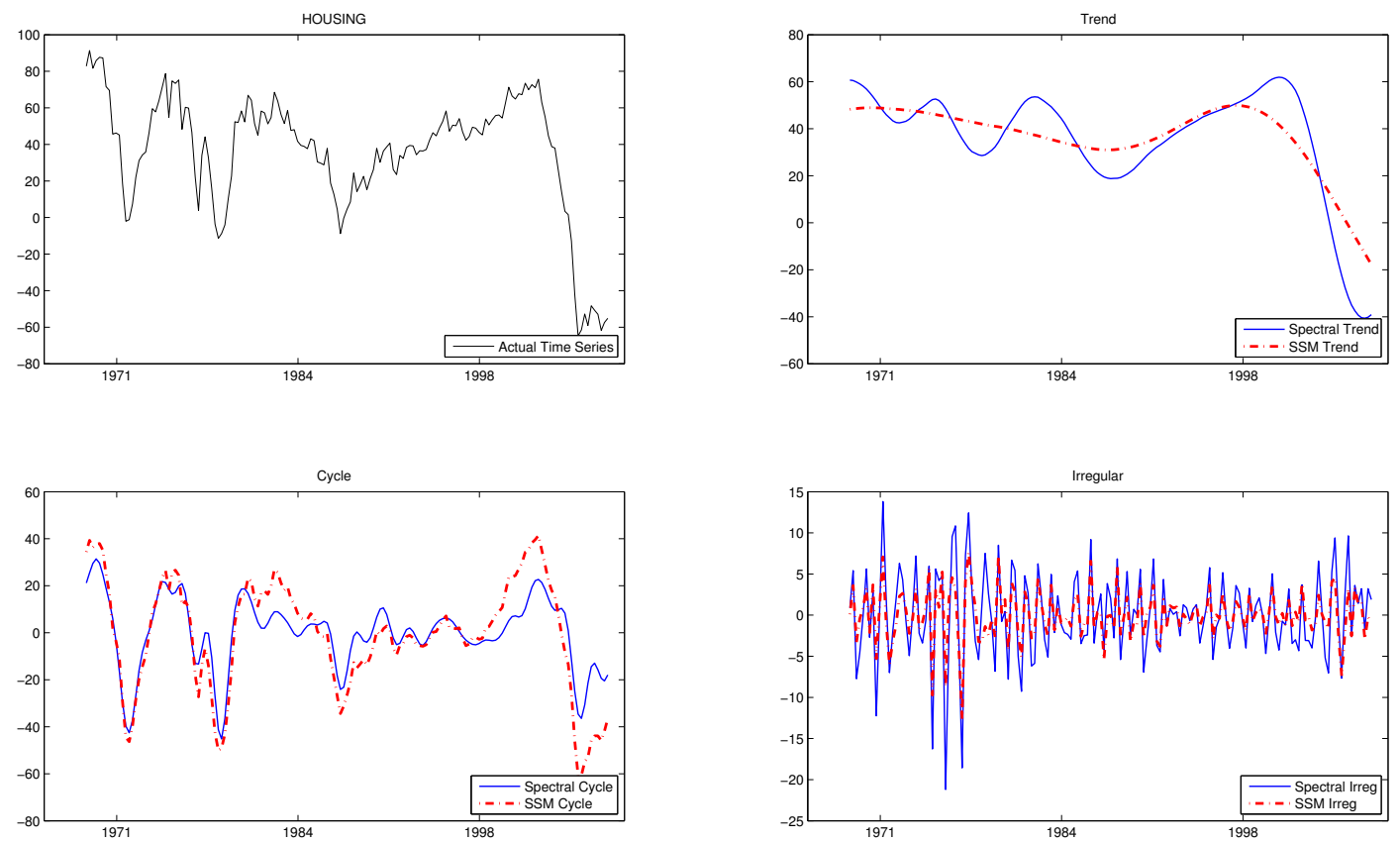

Figure A4: Housing Starts 


\section{Appendix B Alternative Frequency Filters}

Table B1: Forecast Regressions $(h=1)$ Based On Alternative Frequency Filters

\begin{tabular}{|c|c|c|c|c|c|c|c|}
\hline & \multicolumn{4}{|c|}{ Estimate (Std. error) } & \multicolumn{3}{|c|}{ Estimate (Std. error) } \\
\hline & intercept & trend & cycle & irreg. & trend & cycle & irreg. \\
\hline & \multicolumn{7}{|c|}{ Christiano-Fitzgerald filter } \\
\hline NGDP & $\begin{array}{c}-0.749 \\
(0.482) \\
2.420\end{array}$ & $\begin{array}{c}1.001 \\
(0.001) \\
1.514\end{array}$ & $\begin{array}{c}0.969 \\
(0.036) \\
0.715\end{array}$ & $\begin{array}{c}0.182^{*} \\
(0.138) \\
35.188\end{array}$ & $\begin{array}{l}1.000^{*} \\
(0.000) \\
11.163\end{array}$ & $\begin{array}{c}0.971 \\
(0.037) \\
0.639\end{array}$ & $\begin{array}{c}0.182^{*} \\
(0.140) \\
34.043\end{array}$ \\
\hline PGDP & $\begin{array}{c}-0.729 \\
(0.376) \\
3.759\end{array}$ & $\begin{array}{c}1.001 \\
(0.001) \\
3.646\end{array}$ & $\begin{array}{c}1.003 \\
(0.040) \\
0.004\end{array}$ & $\begin{array}{c}-0.139^{*} \\
(0.158) \\
51.905\end{array}$ & $\begin{array}{c}1.000 \\
(0.000) \\
1.070\end{array}$ & $\begin{array}{c}1.001 \\
(0.042) \\
0.000\end{array}$ & $\begin{array}{c}-0.138^{*} \\
(0.168) \\
46.166\end{array}$ \\
\hline UNEMP & $\begin{array}{c}1.280 \\
(1.404) \\
0.832\end{array}$ & $\begin{array}{c}0.997 \\
(0.008) \\
0.128\end{array}$ & $\begin{array}{c}0.959^{*} \\
(0.014) \\
9.073\end{array}$ & $\begin{array}{l}0.508^{*} \\
(0.099) \\
24.839\end{array}$ & $\begin{array}{c}1.004^{*} \\
(0.001) \\
20.765\end{array}$ & $\begin{array}{c}0.958^{*} \\
(0.014) \\
9.328\end{array}$ & $\begin{array}{c}0.508^{*} \\
(0.100) \\
24.370\end{array}$ \\
\hline INDPROD & $\begin{array}{c}-1.451 \\
(1.493) \\
0.944\end{array}$ & $\begin{array}{c}1.003 \\
(0.003) \\
0.935\end{array}$ & $\begin{array}{c}0.953 \\
(0.024) \\
3.687\end{array}$ & $\begin{array}{l}0.425^{*} \\
(0.162) \\
12.654\end{array}$ & $\begin{array}{c}1.000 \\
(0.000) \\
0.016\end{array}$ & $\begin{array}{c}0.954 \\
(0.024) \\
3.594\end{array}$ & $\begin{array}{c}0.426^{*} \\
(0.161) \\
12.777\end{array}$ \\
\hline HOUSING & $\begin{array}{c}1.232 \\
(0.661) \\
3.471\end{array}$ & $\begin{array}{l}0.944^{*} \\
(0.014) \\
16.455\end{array}$ & $\begin{array}{c}0.908^{*} \\
(0.027) \\
11.897\end{array}$ & $\begin{array}{l}0.230^{*} \\
(0.115) \\
44.493\end{array}$ & $\begin{array}{l}0.964^{*} \\
(0.008) \\
19.145\end{array}$ & $\begin{array}{l}0.908^{*} \\
(0.027) \\
11.768\end{array}$ & $\begin{array}{c}0.230^{*} \\
(0.116) \\
44.338\end{array}$ \\
\hline & \multicolumn{7}{|c|}{ Butterworth filter } \\
\hline NGDP & $\begin{array}{c}-0.753 \\
(0.475) \\
2.515\end{array}$ & $\begin{array}{c}1.001 \\
(0.001) \\
1.580\end{array}$ & $\begin{array}{c}1.004 \\
(0.039) \\
0.010\end{array}$ & $\begin{array}{l}0.017^{*} \\
(0.170) \\
33.365\end{array}$ & $\begin{array}{l}1.000^{*} \\
(0.000) \\
11.735\end{array}$ & $\begin{array}{c}1.004 \\
(0.040) \\
0.013\end{array}$ & $\begin{array}{c}0.017^{*} \\
(0.172) \\
32.490\end{array}$ \\
\hline PGDP & $\begin{array}{c}-0.716^{*} \\
(0.363) \\
3.881\end{array}$ & $\begin{array}{c}1.001 \\
(0.001) \\
3.762\end{array}$ & $\begin{array}{c}1.038 \\
(0.040) \\
0.892\end{array}$ & $\begin{array}{c}-0.320^{*} \\
(0.152) \\
75.130\end{array}$ & $\begin{array}{c}1.000 \\
(0.000) \\
1.164\end{array}$ & $\begin{array}{c}1.039 \\
(0.041) \\
0.882\end{array}$ & $\begin{array}{c}-0.320^{*} \\
(0.162) \\
66.659\end{array}$ \\
\hline UNEMP & $\begin{array}{c}0.678 \\
(1.735) \\
0.153\end{array}$ & $\begin{array}{c}1.001 \\
(0.009) \\
0.004\end{array}$ & $\begin{array}{c}0.961^{*} \\
(0.016) \\
5.672\end{array}$ & $\begin{array}{c}0.457^{*} \\
(0.102) \\
28.376\end{array}$ & $\begin{array}{l}1.004^{*} \\
(0.001) \\
21.873\end{array}$ & $\begin{array}{c}0.959^{*} \\
(0.016) \\
6.988\end{array}$ & $\begin{array}{c}0.458^{*} \\
(0.102) \\
27.953\end{array}$ \\
\hline INDPROD & $\begin{array}{c}-1.476 \\
(1.483) \\
0.991\end{array}$ & $\begin{array}{c}1.003 \\
(0.003) \\
0.983\end{array}$ & $\begin{array}{c}0.959 \\
(0.030) \\
1.945\end{array}$ & $\begin{array}{l}0.330^{*} \\
(0.198) \\
11.433\end{array}$ & $\begin{array}{c}1.000 \\
(0.000) \\
0.016\end{array}$ & $\begin{array}{c}0.959 \\
(0.030) \\
1.806\end{array}$ & $\begin{array}{c}0.329^{*} \\
(0.198) \\
11.496\end{array}$ \\
\hline HOUSING & $\begin{array}{c}1.168 \\
(0.680) \\
2.953\end{array}$ & $\begin{array}{l}0.946^{*} \\
(0.015) \\
12.278\end{array}$ & $\begin{array}{c}0.928^{*} \\
(0.036) \\
4.001\end{array}$ & $\begin{array}{l}0.095^{*} \\
(0.139) \\
42.503\end{array}$ & $\begin{array}{c}0.967^{*} \\
(0.009) \\
14.606\end{array}$ & $\begin{array}{c}0.916^{*} \\
(0.036) \\
5.458\end{array}$ & $\begin{array}{c}0.099^{*} \\
(0.138) \\
42.474\end{array}$ \\
\hline
\end{tabular}

This table shows the parameter estimates in forecast regression (13) of the professional forecasts on the Christiano-Fitzgerald filter decomposition and the Butterworth filter decomposition. For notes, see Table 6. 


\section{Appendix C Forecast Regressions First Differ- ences}

Table C1: Forecast Regressions $(h=1)$ Based On Spectral Analysis on First Differences

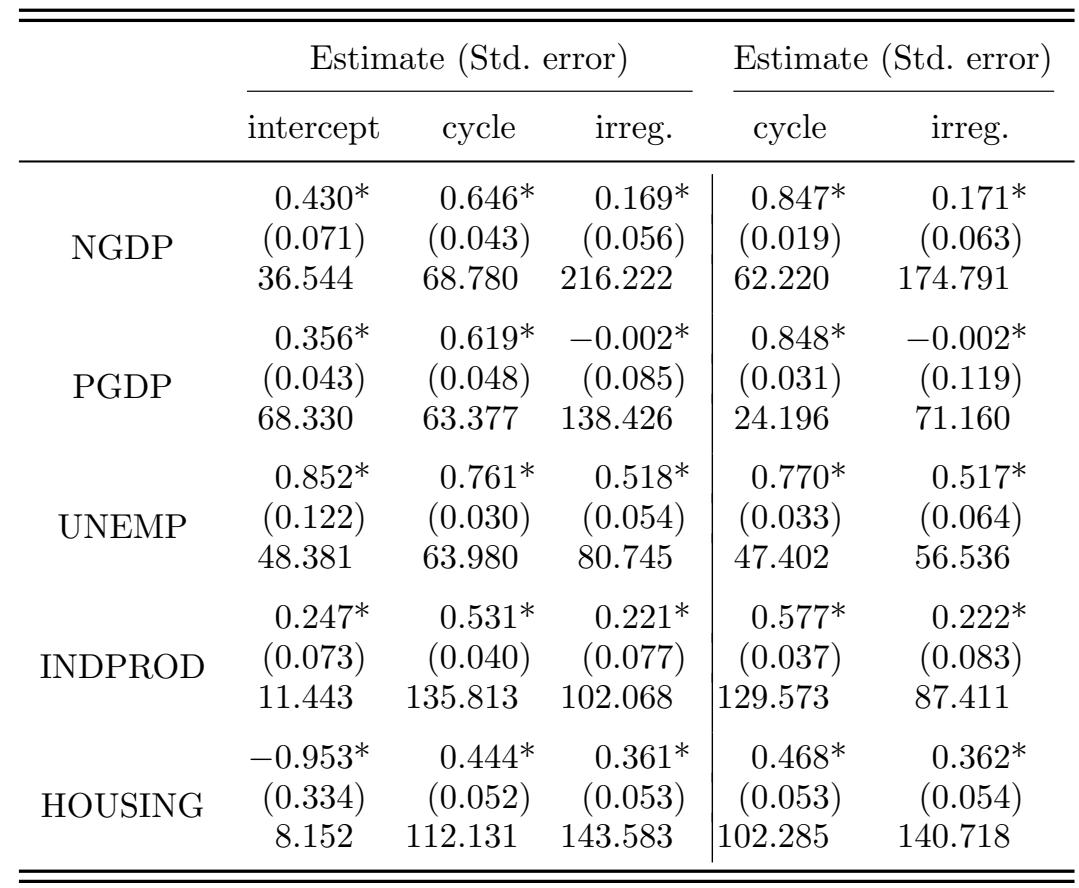

This table shows the parameter estimates in forecast regression (13) with first differences of the series instead of levels, of the professional forecasts on the low-pass filter decomposition, with and without intercept. Since we take first differences, the trend is removed from the forecast regression. For additional information, see the note following Table 6 . 


\section{Appendix D Multi-step-ahead Forecasts}

Table D1: Forecast Regressions Based On Spectral Analysis for $h=2$

\begin{tabular}{|c|c|c|c|c|c|c|c|}
\hline & \multicolumn{4}{|c|}{ Estimate (Std. error) } & \multicolumn{3}{|c|}{ Estimate (Std. error) } \\
\hline & intercept & trend & cycle & irreg. & trend & cycle & irreg. \\
\hline NGDP & $\begin{array}{c}-2.317^{*} \\
(0.933) \\
6.168\end{array}$ & $\begin{array}{c}1.002^{*} \\
(0.001) \\
4.999\end{array}$ & $\begin{array}{c}0.820^{*} \\
(0.065) \\
7.640\end{array}$ & $\begin{array}{c}-0.362^{*} \\
(0.196) \\
48.545\end{array}$ & $\begin{array}{c}1.000^{*} \\
(0.000) \\
9.255\end{array}$ & $\begin{array}{c}0.827^{*} \\
(0.066) \\
6.857\end{array}$ & $\begin{array}{c}-0.374^{*} \\
(0.207) \\
44.203\end{array}$ \\
\hline PGDP & $\begin{array}{c}-1.085 \\
(0.941) \\
1.331\end{array}$ & $\begin{array}{c}1.002 \\
(0.002) \\
1.290\end{array}$ & $\begin{array}{c}0.991 \\
(0.059) \\
0.024\end{array}$ & $\begin{array}{c}-0.504^{*} \\
(0.227) \\
43.901\end{array}$ & $\begin{array}{c}1.000 \\
(0.000) \\
0.514\end{array}$ & $\begin{array}{c}1.002 \\
(0.062) \\
0.001\end{array}$ & $\begin{array}{c}-0.520^{*} \\
(0.236) \\
41.508\end{array}$ \\
\hline UNEMP & $\begin{array}{c}3.951 \\
(3.758) \\
1.105\end{array}$ & $\begin{array}{c}0.984 \\
(0.021) \\
0.546\end{array}$ & $\begin{array}{c}0.812^{*} \\
(0.035) \\
29.244\end{array}$ & $\begin{array}{c}-0.227^{*} \\
(0.222) \\
30.634\end{array}$ & $\begin{array}{c}1.006^{*} \\
(0.002) \\
8.066\end{array}$ & $\begin{array}{c}0.800^{*} \\
(0.033) \\
37.562\end{array}$ & $\begin{array}{c}-0.211^{*} \\
(0.221) \\
30.036\end{array}$ \\
\hline INDPROD & $\begin{array}{c}-4.779 \\
(3.456) \\
1.913\end{array}$ & $\begin{array}{c}1.009 \\
(0.006) \\
2.025\end{array}$ & $\begin{array}{c}0.766^{*} \\
(0.053) \\
19.653\end{array}$ & $\begin{array}{c}-0.207^{*} \\
(0.246) \\
24.055\end{array}$ & $\begin{array}{c}1.000 \\
(0.000) \\
0.837\end{array}$ & $\begin{array}{c}0.765^{*} \\
(0.053) \\
19.796\end{array}$ & $\begin{array}{c}-0.210^{*} \\
(0.240) \\
25.360\end{array}$ \\
\hline HOUSING & $\begin{array}{c}6.323^{*} \\
(1.247) \\
25.722\end{array}$ & $\begin{array}{c}0.852^{*} \\
(0.031) \\
22.887\end{array}$ & $\begin{array}{c}0.638^{*} \\
(0.060) \\
36.707\end{array}$ & $\begin{array}{c}-0.300^{*} \\
(0.129) \\
102.017\end{array}$ & $\begin{array}{c}0.986 \\
(0.015) \\
0.865\end{array}$ & $\begin{array}{c}0.537^{*} \\
(0.056) \\
69.448\end{array}$ & $\begin{array}{c}-0.268^{*} \\
(0.128) \\
98.129\end{array}$ \\
\hline
\end{tabular}

This table shows the parameter estimates in forecast regression (13) with $h=2$, of the professional forecasts on the low-pass filter decomposition, with and without intercept. For additional information, see the note following Table 6 . 
Table D2: Forecast Regressions Based On Spectral Analysis for $h=3$

\begin{tabular}{|c|c|c|c|c|c|c|c|}
\hline & \multicolumn{4}{|c|}{ Estimate (Std. error) } & \multicolumn{3}{|c|}{ Estimate (Std. error) } \\
\hline & intercept & trend & cycle & irreg. & trend & cycle & irreg. \\
\hline NGDP & $\begin{array}{c}-3.557^{*} \\
(1.240) \\
8.222\end{array}$ & $\begin{array}{c}1.004^{*} \\
(0.001) \\
7.104\end{array}$ & $\begin{array}{c}0.589^{*} \\
(0.094) \\
19.319\end{array}$ & $\begin{array}{c}-0.396^{*} \\
(0.257) \\
29.536\end{array}$ & $\begin{array}{c}1.000^{*} \\
(0.000) \\
4.436\end{array}$ & $\begin{array}{c}0.594^{*} \\
(0.093) \\
18.917\end{array}$ & $\begin{array}{c}-0.413^{*} \\
(0.267) \\
27.960\end{array}$ \\
\hline PGDP & $\begin{array}{c}-2.924 \\
(1.524) \\
3.679\end{array}$ & $\begin{array}{c}1.005 \\
(0.003) \\
3.723\end{array}$ & $\begin{array}{c}0.961 \\
(0.095) \\
0.170\end{array}$ & $\begin{array}{c}-0.517^{*} \\
(0.318) \\
22.740\end{array}$ & $\begin{array}{c}1.000 \\
(0.000) \\
0.187\end{array}$ & $\begin{array}{c}0.989 \\
(0.102) \\
0.011\end{array}$ & $\begin{array}{c}-0.531^{*} \\
(0.346) \\
19.523\end{array}$ \\
\hline UNEMP & $\begin{array}{c}4.160 \\
(5.931) \\
0.492\end{array}$ & $\begin{array}{c}0.981 \\
(0.033) \\
0.310\end{array}$ & $\begin{array}{c}0.632^{*} \\
(0.060) \\
37.578\end{array}$ & $\begin{array}{c}-0.336^{*} \\
(0.323) \\
17.080\end{array}$ & $\begin{array}{c}1.004 \\
(0.003) \\
1.776\end{array}$ & $\begin{array}{c}0.620^{*} \\
(0.058) \\
43.577\end{array}$ & $\begin{array}{c}-0.318^{*} \\
(0.322) \\
16.758\end{array}$ \\
\hline INDPROD & $\begin{array}{c}-4.581 \\
(4.816) \\
0.905\end{array}$ & $\begin{array}{c}1.009 \\
(0.008) \\
1.072\end{array}$ & $\begin{array}{c}0.507^{*} \\
(0.074) \\
44.229\end{array}$ & $\begin{array}{c}-0.451^{*} \\
(0.299) \\
23.500\end{array}$ & $\begin{array}{c}1.001 \\
(0.000) \\
3.630\end{array}$ & $\begin{array}{c}0.506^{*} \\
(0.074) \\
45.111\end{array}$ & $\begin{array}{c}-0.455^{*} \\
(0.293) \\
24.704\end{array}$ \\
\hline HOUSING & $\begin{array}{c}10.425^{*} \\
(1.739) \\
35.925\end{array}$ & $\begin{array}{c}0.790^{*} \\
(0.042) \\
25.219\end{array}$ & $\begin{array}{c}0.387^{*} \\
(0.076) \\
64.405\end{array}$ & $\begin{array}{c}-0.277^{*} \\
(0.156) \\
66.677\end{array}$ & $\begin{array}{c}1.010 \\
(0.018) \\
0.340\end{array}$ & $\begin{array}{c}0.220^{*} \\
(0.069) \\
128.258\end{array}$ & $\begin{array}{c}-0.227^{*} \\
(0.166) \\
54.812\end{array}$ \\
\hline
\end{tabular}

This table shows the parameter estimates in forecast regression (13) with $h=3$, of the professional forecasts on the low-pass filter decomposition, with and without intercept. For additional information, see the note following Table 6 . 
Table D3: Forecast Regressions Based On Spectral Analysis for $h=4$

\begin{tabular}{|c|c|c|c|c|c|c|c|}
\hline & \multicolumn{4}{|c|}{ Estimate (Std. error) } & \multicolumn{3}{|c|}{ Estimate (Std. error) } \\
\hline & intercept & trend & cycle & irreg. & trend & cycle & irreg. \\
\hline NGDP & $\begin{array}{c}-4.839^{*} \\
(1.507) \\
10.313\end{array}$ & $\begin{array}{c}1.005^{*} \\
(0.002) \\
9.321\end{array}$ & $\begin{array}{c}0.283^{*} \\
(0.105) \\
46.936\end{array}$ & $\begin{array}{c}-0.134^{*} \\
(0.279) \\
16.468\end{array}$ & $\begin{array}{c}1.000 \\
(0.000) \\
1.505\end{array}$ & $\begin{array}{c}0.285^{*} \\
(0.104) \\
46.996\end{array}$ & $\begin{array}{c}-0.138^{*} \\
(0.296) \\
14.797\end{array}$ \\
\hline PGDP & $\begin{array}{c}-5.390^{*} \\
(2.160) \\
6.226\end{array}$ & $\begin{array}{c}1.009^{*} \\
(0.004) \\
6.395\end{array}$ & $\begin{array}{c}0.891 \\
(0.134) \\
0.663\end{array}$ & $\begin{array}{c}-0.422^{*} \\
(0.386) \\
13.591\end{array}$ & $\begin{array}{c}1.000 \\
(0.000) \\
0.037\end{array}$ & $\begin{array}{c}0.936 \\
(0.150) \\
0.185\end{array}$ & $\begin{array}{c}-0.404^{*} \\
(0.428) \\
10.790\end{array}$ \\
\hline UNEMP & $\begin{array}{c}5.300 \\
(7.917) \\
0.448\end{array}$ & $\begin{array}{c}0.971 \\
(0.044) \\
0.417\end{array}$ & $\begin{array}{c}0.413^{*} \\
(0.085) \\
48.170\end{array}$ & $\begin{array}{c}-0.357^{*} \\
(0.382) \\
12.636\end{array}$ & $\begin{array}{c}1.000 \\
(0.004) \\
0.007\end{array}$ & $\begin{array}{c}0.397^{*} \\
(0.080) \\
56.375\end{array}$ & $\begin{array}{c}-0.336^{*} \\
(0.381) \\
12.272\end{array}$ \\
\hline INDPROD & $\begin{array}{c}-3.291 \\
(5.810) \\
0.321\end{array}$ & $\begin{array}{c}1.007 \\
(0.010) \\
0.487\end{array}$ & $\begin{array}{c}0.223^{*} \\
(0.085) \\
84.426\end{array}$ & $\begin{array}{c}-0.084^{*} \\
(0.320) \\
11.484\end{array}$ & $\begin{array}{c}1.001^{*} \\
(0.000) \\
8.790\end{array}$ & $\begin{array}{c}0.222^{*} \\
(0.084) \\
86.014\end{array}$ & $\begin{array}{c}-0.087^{*} \\
(0.316) \\
11.840\end{array}$ \\
\hline HOUSING & $\begin{array}{c}15.014^{*} \\
(2.164) \\
48.149\end{array}$ & $\begin{array}{c}0.715^{*} \\
(0.051) \\
31.553\end{array}$ & $\begin{array}{c}0.171^{*} \\
(0.081) \\
104.963\end{array}$ & $\begin{array}{c}-0.090^{*} \\
(0.161) \\
45.799\end{array}$ & $\begin{array}{c}1.032 \\
(0.020) \\
2.492\end{array}$ & $\begin{array}{c}-0.072^{*} \\
(0.073) \\
213.014\end{array}$ & $\begin{array}{c}-0.012^{*} \\
(0.202) \\
25.032\end{array}$ \\
\hline
\end{tabular}

This table shows the parameter estimates in forecast regression (13) with $h=4$, of the professional forecasts on the low-pass filter decomposition, with and without intercept. For additional information, see the note following Table 6 .

\section{Appendix E Sensitivity Analysis}

In Subsection 4.2 we show the sensitivity of the estimated coefficients in the forecast regression of nominal GDP to the standard deviation of the variance of the estimated irregular component in the state space framework. Here we show the sensitivities of the coefficients of the components of the other variables; GDP price index (PGDP), unemployment (UNEMP), industrial production index (INDPROD), and housing starts (HOUSING). Each figure corresponding to a variable consists of four windows; the coefficients of the intercept, trend, business-cycle, and irregular component. The blue lines indicate the value of the estimated coefficient with error bands of one standard error, for different values of the standard deviation of the variance of the estimated irregular component. The error bands are constructed with two-step standard errors. The red asterisks show the estimated coefficient at the value of the standard deviation of the variance of the estimated irregular 
component in the low-pass filter.
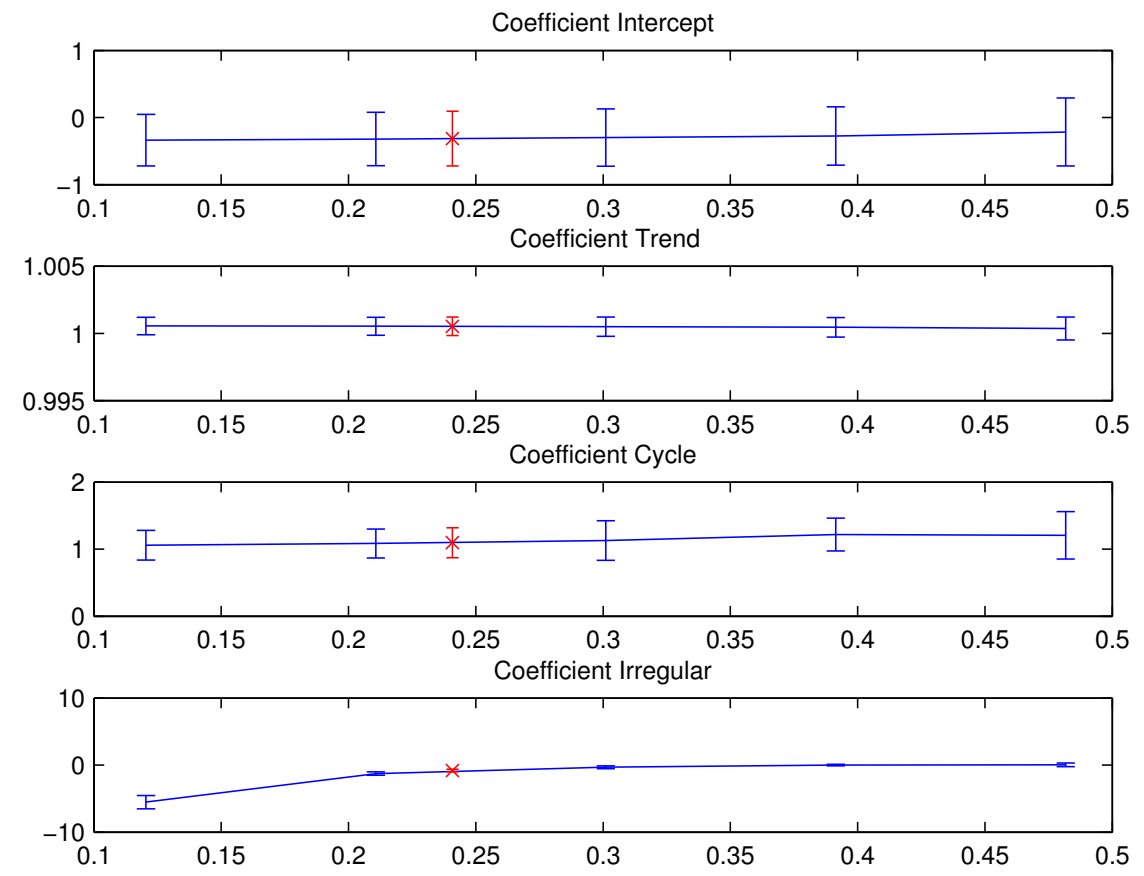

Figure E1: GDP Price Index 

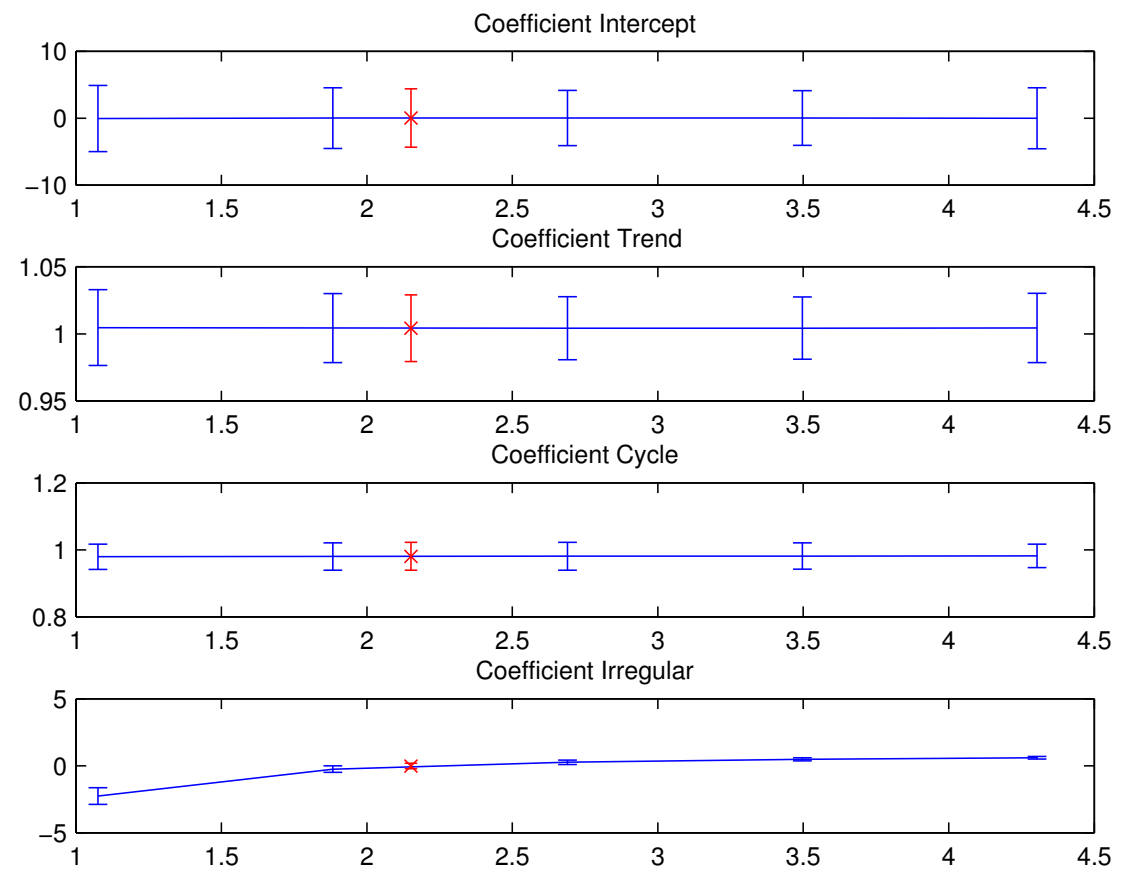

Figure E2: Unemployment
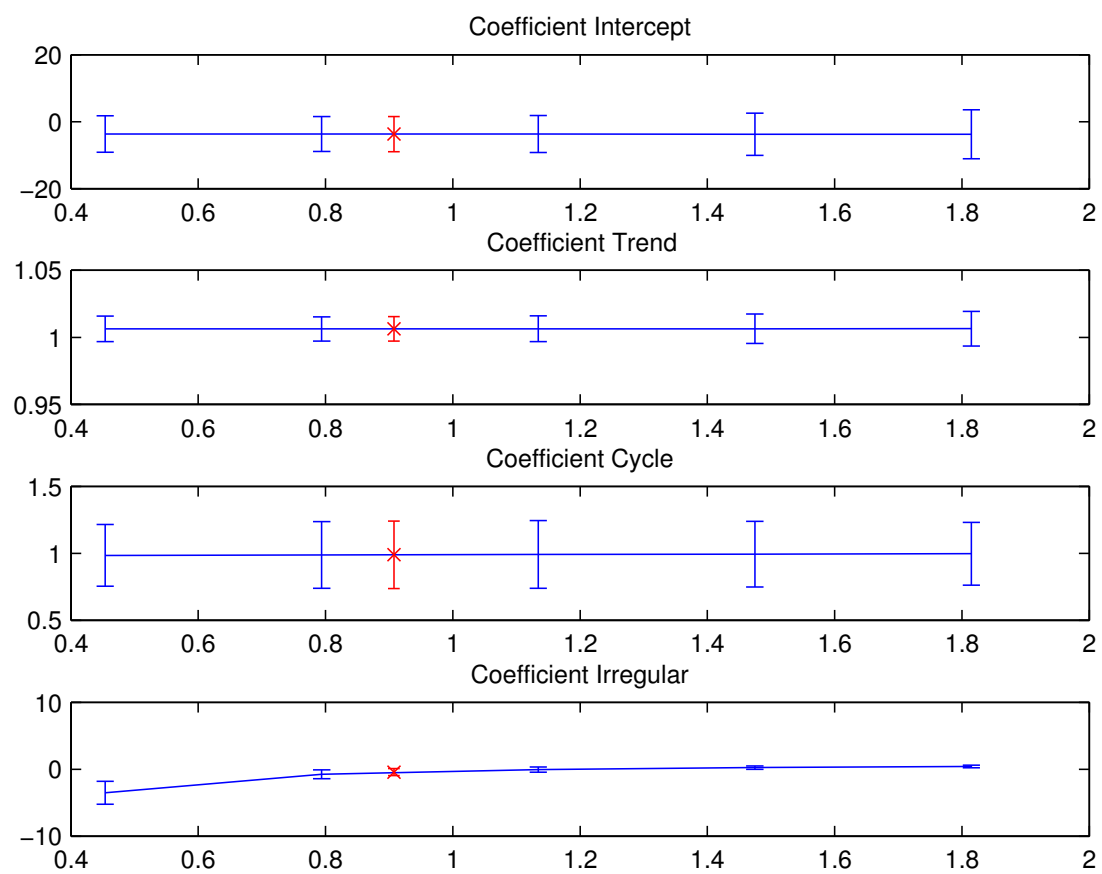

Figure E3: Industrial Production Index 

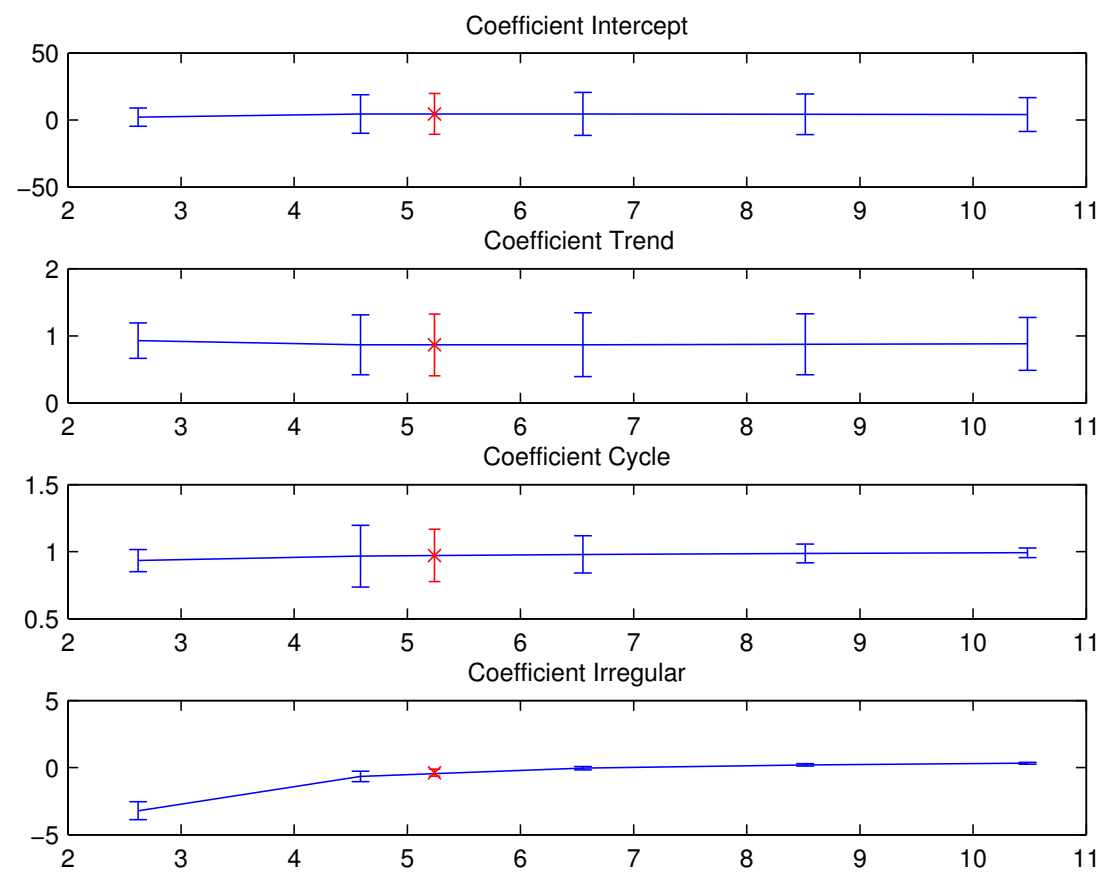

Figure E4: Housing Starts 